Illinois State University

ISU ReD: Research and eData

Theses and Dissertations

$2-4-2020$

\title{
"where Words Fail, Music Speaks": Emotion Regulation Strategies Using Music When Experiencing Sadness
}

Kendall M. Ladd

Illinois State University, emeraldstone594@gmail.com

Follow this and additional works at: https://ir.library.illinoisstate.edu/etd

Part of the Music Commons, and the Psychology Commons

\section{Recommended Citation}

Ladd, Kendall M., "'where Words Fail, Music Speaks": Emotion Regulation Strategies Using Music When Experiencing Sadness" (2020). Theses and Dissertations. 1199.

https://ir.library.illinoisstate.edu/etd/1199

This Thesis is brought to you for free and open access by ISU ReD: Research and eData. It has been accepted for inclusion in Theses and Dissertations by an authorized administrator of ISU ReD: Research and eData. For more information, please contact ISUReD@ilstu.edu. 


\title{
“WHERE WORDS FAIL, MUSIC SPEAKS": EMOTION REGULATION STRATEGIES USING MUSIC WHEN EXPERIENCING SADNESS
}

\author{
Kendall M. Ladd
}

\section{Pages}

Past literature has suggested that individuals use the emotion regulation strategies of catharsis, emotional support, understanding emotions, and mood congruency when deciding to listen to sad music when feeling sad (Friedman et al., 2012; Garrido \& Schubert, 2013; Sedikides, 1992; Taylor \& Friedman, 2015; van Goethem \& Sloboda, 2011). This thesis sought to confirm this by comparing these four strategies to revival, another emotion regulation strategy that uses happy music instead of sad music.

The final sample of participants consisted of 122 undergraduate and graduate students at a Midwestern university. Participants completed questionnaires designed to measure how they typically regulate their emotions by listening to music, why they typically choose to listen to sad music, and a measure of current sadness before watching a sad film clip. After this clip, participants rated their feelings of sadness again and were randomly assigned one of the five emotion regulation strategies to use when selecting a song of their choice to listen to. After listening to music, participants completed additional questionnaires used to measure current sadness for a final time, their reasons for selecting their song of choice, and their satisfaction with their song choice. External raters were also utilized to rate the emotionality, arousal, and speed of the participant selected songs. 
Results indicated that all participants, regardless of emotion regulation strategy used, experienced significant decreases in feelings of sadness after listening to their songs of choice. There were no significant differences in how satisfied participants were with their song choices. Based on ratings provided by the external raters, song choices differed in that songs chosen by participants in the catharsis, emotional support, understanding emotions, and mood congruency conditions were rated as significantly sadder, calmer, and slower than songs chosen by participants in the revival condition.

These results suggest that people choose to listen to sad music when they use catharsis, emotional support, understanding emotions, and mood congruency as emotion regulation strategies when experiencing feelings of sadness. Future research would benefit from examining these emotion regulation strategies in other sadness-inducing situations and identifying any differences in their success.

KEYWORDS: emotions; emotion regulation; music; sadness; catharsis; emotional support; understanding emotions; mood congruency; revival 
“WHERE WORDS FAIL, MUSIC SPEAKS": EMOTION REGULATION STRATEGIES USING MUSIC WHEN EXPERIENCING SADNESS

KENDALL M. LADD

A Thesis Submitted in Partial Fulfillment of the Requirements for the Degree of MASTER OF SCIENCE

Department of Psychology

ILLINOIS STATE UNIVERSITY 
(C) 2020 Kendall M. Ladd 
“WHERE WORDS FAIL, MUSIC SPEAKS": EMOTION REGULATION STRATEGIES USING MUSIC WHEN EXPERIENCING SADNESS

KENDALL M. LADD

COMMITTEE MEMBERS:

Jeffrey H. Kahn, Chair

Eric Wesselmann 


\section{ACKNOWLEDGMENTS}

The development and completion of this thesis would not have been possible without the unwavering guidance, support, and encouragement from a number of people. First and foremost, I must thank my thesis chair, Dr. Jeffrey Kahn, for providing his expertise when refining this topic and experimental methodology, and for his patience and guidance that helped motivate me to go above and beyond what I thought I was capable of. I would also like to thank my committee member, Dr. Eric Wesselmann, for assisting in the development and revision processes and providing some of the resources necessary to complete data collection. Finally, to Dr. Joe Hilgard, thank you for challenging me to raise the quality and complexity of my writing and research. I must also thank Destiny Feltner-Williams, Amanda Martin, and Brooke White for helping me gather high-quality data, without whom there would not have been data to analyze.

There have been so many other people who have provided me with love, support, and encouragement. To all of my friends, near and far, thank you for always thinking to check-in and provide words of encouragement, even after doing so many times before. To all of those in my cohort, I am so grateful to you for always providing your support, even when you may have needed mine more. To Kim ("KC") and David Congdon, I can't begin to convey how thankful I am to you both for always providing an endless supply of laughter and ice cream, and for keeping me grounded in times of stress and discouragement.

This thesis is dedicated to my parents, Marlin and Nancy Ladd, and sister, Caitlin Ladd, for always believing in me and reminding me that I am capable of anything. Words are unable to express my overwhelming gratitude to them, and to everyone, who has stuck with me throughout this thesis process these past two years. Thank you.

K. M. L. 


\section{CONTENTS}

Page

ACKNOWLEDGMENTS

TABLES

FIGURES - vi

$\begin{array}{ll}\text { CHAPTER I: INTRODUCTION } & 1\end{array}$

CHAPTER II: REVIEW OF RELATED LITERATURE 4

Emotion Regulation $\quad 4$

Emotions

Emotion Regulation $\quad 6$

Emotion Regulation Strategy Selection 9

$\begin{array}{ll}\text { Reappraisal } & 10\end{array}$

$\begin{array}{ll}\text { Suppression } & 11\end{array}$

Music and Emotion Regulation $\quad 12$

$\begin{array}{ll}\text { Music and Emotion } & 12\end{array}$

Music Listening and Emotion Regulation $\quad 15$

Purpose of the Present Study 19

$\begin{array}{ll}\text { Hypotheses } & 21\end{array}$

CHAPTER III: METHODOLOGY 23

$\begin{array}{ll}\text { Participants } & 23\end{array}$

$\begin{array}{ll}\text { Materials } & 24\end{array}$

$\begin{array}{ll}\text { Film Stimulus } & 24\end{array}$

$\begin{array}{ll}\text { Song Selection } & 24\end{array}$ 
Measures

Demographic Information

Sadness

Emotion Regulation and Music

Typical Music Choice

Song Satisfaction

Experimental Song Selection

External Song Rating

Procedure

CHAPTER IV: RESULTS

Manipulation Checks

Catharsis

Emotional Support

Understanding Emotions

Mood Congruency

Revival

Qualitative Data Analysis

Emotion Regulation Preferences

Sadness

Reasons for Listening to Sad Music

Song Satisfaction

Song Emotionality

Happiness 
Typical Emotion Regulation Preferences $\quad 52$

Emotion Regulation Strategies When Choosing Music 53

Emotion Regulation Strategy Success

$\begin{array}{ll}\text { Song Emotionality } & 56\end{array}$

$\begin{array}{ll}\text { Limitations } & 58\end{array}$

$\begin{array}{ll}\text { Future Directions } & 61\end{array}$

$\begin{array}{ll}\text { Conclusions } & 62\end{array}$

$\begin{array}{lc}\text { REFERENCES } & 64\end{array}$

APPENDIX A: DEMOGRAPHIC INFORMATION QUESTIONNAIRE 75

APPENDIX B: MODIFIED BRIEF MUSIC IN MOOD REGULATION SCALE (B-MMR) 76

APPENDIX C: REASONS FOR LISTENING TO SAD MUSIC QUESTIONNAIRE 77

APPENDIX D: SONG SATISFACTION SCALE $\quad 78$

$\begin{array}{ll}\text { APPENDIX E: SONG SELECTION SURVEY } & 79\end{array}$

APPENDIX F: SONG RATING SCALES $\quad 80$ 


\section{TABLES}

Table

Page

1. First Manipulation Check Using Response Frequencies for Each Set of Song Selection Instructions According to Experimental Condition

2. Second Manipulation Check Using Response Frequencies for Each Set of Song Selection Instructions According to Experimental Condition

3. Frequencies of Participant Responses for Each Qualitative Response Category by Experimental Condition

4. Means and Standard Deviations for Participant Sadness Before and After the Film Clip and After Music Listening Across Experimental Conditions

5. Means and Standard Deviations for Emotionality Ratings Completed by External Ratings for Songs Selected by Participants in Each of the Emotion Regulation Conditions 


\section{FIGURES}

Figure

Page

1. Average ratings for how each set of song selection instructions played into the music selection decisions for participants in the different experimental conditions.

2. Average preference for typical use of nine emotion regulation strategies for participants in the separate emotion regulation conditions.

3. Change in average sadness from before and after the film clip and after listening to music.

4. Average likelihood of listening to sad music when feeling sad for each of the nine reasons included on the Reasons for Listening to Sad Music Questionnaire. 


\section{CHAPTER I: INTRODUCTION}

Immediately after birth, individuals are able to begin forming an understanding of their emotions, starting with the recognition of pleasure and displeasure (Barrett, Mesquita, Ochsner, $\&$ Gross, 2007). As we age, our understanding of our emotions becomes more complex when we start to distinguish between physiological changes and continue to have more extensive experiences (Barrett et al., 2007; Barrett, Quigley, Bliss-Moreau, \& Aronson, 2004). Regardless of the complexity of an individual's emotional understanding, it is ultimately how an individual perceives a situation that determines his or her emotional response (Gross, 1999; Schachter \& Singer, 1962). In addition, based on personal and situational factors, individuals may choose to implement an emotion regulation strategy in order to enhance or diminish the emotion they are experiencing (Gross, 1998a; McRae et al., 2017; Millgram, Joormann, Huppert, \& Tamir, 2015; Tamir, 2016).

Emotion regulation is used in order to enhance positive emotions and diminish negative ones (e.g., Gross, 1998b; Millgram et al., 2015; Tamir, 2016; van Goethem \& Sloboda, 2011). Five emotion regulation strategies have been outlined using Gross's (1998b) process model of emotion regulation: situation selection, situation modification, attentional deployment, cognitive change (i.e., reappraisal), and response modulation (i.e., expressive suppression). An individual's decision to implement one of these strategies over another can be driven by a number of things. These include an individual's motivation behind implementing emotion regulation, how difficult it is to implement one of these emotion regulation strategies, and even an individual's beliefs about his or her emotions (Ford \& Gross, 2018; Milyavsky et al., 2018; Tamir, 2016). Regardless of the specific emotion regulation strategy selected by an individual, there are multiple methods an individual can use in order to achieve emotion regulation. 
Over the past few decades, the amount of research examining music's relation with emotions and emotion regulation has skyrocketed. Specifically targeting music listening, emotivists, cognitivists, and other researchers have divergent views of music's ability to convey and induce emotions (Sachs, Damasio, \& Habibi, 2015). Emotivists argue that emotions can be conveyed through music, and that emotions can ultimately be induced via music listening (Sachs et al., 2015). Cognitivists are of the same mind as emotivists regarding music's ability to convey emotions, but instead claim that emotions are not able to be induced (Sachs et al., 2015). Finally, there are those who disagree with both emotivists and cognitivists, alternatively affirming that music can neither convey nor induce emotions and that emotional responses to music are driven by other factors, such as how the listener appraises the music and what emotions the listener believes the music can evoke (Dingle \& Fay, 2017; Juslin \& Laukka, 2004; Mursell, 1971; Robertson, 1934). Despite these differing viewpoints, listening to music is still a successful method to use in order to regulate emotions, whether it is being used adaptively or maladaptively (Chin \& Rickard, 2014; Randall \& Rickard, 2017; Shifriss, Bodner, \& Palgi, 2015; Zavoyskiy, Taylor, \& Friedman, 2016).

Listening to music for the purposes of emotion regulation can occur utilizing any combination of emotional state and music type. The most intriguing of these combinations has been identified as the "tragedy paradox," and refers to the practice of listening to sad music when in a sad emotional state (Sachs et al., 2015). Individuals opt to listen to sad music when feeling sad despite the fact that listening to happy music leads to greater improvements in mood, and they will select sad music over happy music to listen to more often than individuals who are not in a sad emotional state (Chen, Zhou, \& Bryant, 2007; Hunter, Schellenberg, \& Griffith, 2011; Lee, Andrade, \& Palmer, 2013; Randall \& Rickard, 2017; Shifriss et al., 2015; Taruffi \& 
Koelsch, 2014; Zavoyskiy et al., 2016; except O’Malley, Seror III, \& Friedman, 2016). Eight benefits of listening to sad music have been identified, but they were not specifically examined as emotion regulation strategies (Levinson, 1990). Some of these benefits include catharsis, emotional assurance, and emotional communion. More recently, Saarikallio (2008) identified seven emotion regulation strategies (e.g., entertainment, discharge, solace) that are specific to music listening, but these seven strategies do not particularly apply to sad emotional states or the use of sad music. Further, there have been many other studies that have provided a variety of other explanations for why individuals may choose to listen to sad music when feeling sad (e.g., Garrido \& Schubert, 2013; Sedikides, 1992; Stapley, 2014; van Goethem \& Sloboda, 2011). All of this different research suggests four emotion regulation strategies that are utilized by individuals who select sad music to listen to when feeling sad: catharsis, emotional support, understanding emotions, and mood congruency. However, there has not been a single research study distinctly confirming this.

Therefore, the purpose of this study was to streamline all of this different research and confirm these are the four emotion regulation strategies that individuals specifically implement when they are feeling sad and select sad music to listen to. A fifth emotion regulation strategy, revival, was used as a comparison as it is an emotion regulation strategy using happy music. In order to do this, sadness was induced in all study participants, and they were specifically instructed to select a song to listen to that enabled them to regulate their emotions using one of these five strategies. In order to determine the success of these emotion regulation strategies, participants rated their satisfaction with their song choice and how satisfied they felt after listening to it. The emotionality of these participant selected songs was also examined to determine whether these songs were considered "sad." 


\section{CHAPTER II: REVIEW OF RELATED LITERATURE}

\section{Emotion Regulation}

\section{Emotions}

One of the earliest theories of emotion comes from the James-Lange Theory of Emotion. This discharge theory outlines that emotions are the conscious awareness of physiological changes brought about by attitudes towards specific objects or events (Dewey, 1894, 1895; Irons, 1894). It further emphasizes that every emotion has an "object," something that an emotion results from or is aimed towards (Dewey, 1895). In other words, the James-Lange Theory of Emotion claims that an object leads to expressive, physiological changes, and these changes are what lead to the emotion (Stoddart, 1904). However, it should be noted that a single object is not inherently "emotional" as it does not always lead to the same emotion across individuals, nor does it always lead to the same emotion within a single individual across different moments in time (Irons, 1894). More recent research has gone on to expand upon and contradict this theory, breaking emotion down into the individual components that create the emotional experience.

Although the James-Lange Theory identifies physiological changes as the center of all emotional experiences, recent research has found that physiological changes are not equally important in the experience of emotions across all individuals nor can specific physiological changes be attributed to specific emotions (Barrett et al., 2004, 2007). Walter Cannon and Philip Bard were two of the first researchers to challenge the James-Lange Theory, stating that the same physiological changes are experienced across multiple emotions and even unemotional experiences, such as feeling cold or having a fever (Cannon, 1927). The Cannon-Bard Thalamic Theory stresses the role of the thalamus, stating that the pattern of activation in the thalamus is specific to each emotion (Cannon, 1927; Gellhorn, 1961). It is only then that physiological 
changes occur, and they occur simultaneously with the emotional experience (Cannon, 1927). Finally, it was added that the thalamus drives the emotional experience, and the hypothalamus drives emotional expression (Pribram \& Melges, 1969). The James-Lange and Cannon-Bard Thalamic theories were challenged yet again by Schachter and Singer (1962). This two-factor theory of emotion builds on the James-Lange and Cannon-Bard theories by stressing the importance of the cognitive component in the emotional experience (Dror, 2017; Schachter \& Singer, 1962). That is, the Schachter-Singer Theory of Emotions states that if an individual is experiencing physiological changes, he or she will label it as a specific emotional experience based on the situation and cognitive evaluation of the experience (Schachter \& Singer, 1962). In other words, it is how an individual perceives an object or situation that determines the emotional experience he or she has (Gross, 1999).

Even more recently, the concept of core affect has been identified by some researchers as the basis of all emotions. This is the idea that all emotions center around either pleasure or displeasure (Barrett et al., 2007). Pleasure and displeasure have been found to be universal, present at birth, and form a core affect (Barrett et al., 2007). However, core affect alone is unable to fully explain and differentiate between emotions. Physiological changes still play a role in the emotional experience despite not being at the core of emotions. Situational content, however, has been found to be most strongly connected to core affect and helps explain emotional experiences and emotion regulation strategy selection (Barrett et al., 2007; English, Lee, John, \& Gross, 2017; Gross, 2015).

All of these different components were streamlined into what is now known as the modal model of emotion. This model has been widely accepted in research examining emotions and has been used to study a variety of components involved in emotional responding (Barrett, Ochsner, 
\& Gross, 2007; Gross \& Thompson, 2007). In the modal model, an emotion is comprised of three components: a subjective experience, expressive behavior, and physiological changes (Gross \& Thompson, 2007; see also Levinson, 1990). It is triggered by an external or internal situation that is psychologically relevant. This situation is then attended to and appraised by the individual, leading to an emotional response (Barrett et al., 2007; Gross, 2015; Gross \& Thompson, 2007). For example, a student who receives a failing grade on an exam when he or she was hoping to pass may think of him or herself as a failure, start to feel sad, and cry. This emotional response then has the potential of starting a feedback loop, whereby the response can modify the situation and start the process over again (Barrett et al., 2007; Gross, 2015; Gross \& Thompson, 2007). This model created the framework for the process model of emotion regulation (Gross, 2015).

\section{Emotion Regulation}

Emotion regulation is the process by which an individual alters which emotions he or she experiences, when he or she experiences them, and how he or she experiences and expresses them (Gross, 1998b). The direction of emotion regulation is determined by the motivation behind emotion regulation and the emotion regulation goal, with the ultimate goal generally believed to be the decrease of negative emotions and increase of positive ones (e.g., Gross, 1998b; Millgram et al., 2015; Tamir, 2016; van Goethem \& Sloboda, 2011). The motivations behind emotion regulation align individuals towards a specific goal and can be hedonic or instrumental in nature (Tamir, 2016). Hedonic motives aim to balance out an individual's pleasure-pain ratio, with prohedonic motives increasing pleasure and decreasing pain (e.g., watching a happy movie when feeling sad) and contrahedonic motives decreasing pleasure and increasing pain (e.g., watching a sad movie when feeling happy; Tamir, 2016). Instrumental motives are divided into performance 
(i.e., performing optimally), such as a basketball player feeling excited before a big game; epistemic (i.e., obtaining information), including feeling happy when traveling around a new city as a sign that you are safe; social (i.e., promoting social relationships), by appearing happy in order to make new friends; and eudaimonic (i.e., attaining autonomy and competence), which includes watching an aversive training video about power tool safety before starting a new job (Tamir, 2016).

Similar to motivations, emotion regulation goals (i.e., mental representations of potential emotional states) can also be divided into separate categories based on whether they are implicit or explicit in nature. Explicit emotion regulation goals are conscious decisions to change an emotional response, such as using a happy song as a distraction from your sad feelings, while implicit goals are unconscious and more automatic, including labeling the emotion being felt (Braunstein, Gross, \& Ochsner, 2017). Both implicit and explicit goals can be internally or externally generated. Internally generated goals form from an internal stimulus, such as an individual's thoughts, and externally generated goals form from an external stimulus, such as another person (Braunstein et al., 2017).

Emotion regulation can occur at any point during the emotion generation process as outlined by the modal model of emotion, focusing on the antecedents to emotional experiences (antecedent-focused) or on the actual emotional response (response-focused) depending on whether it occurs before or after the emotion is generated (Gross, 1998b, 2001, 2015; Gross \& John, 2003). Gross's (1998b) process model of emotion regulation further divides the antecedent-focus emotion regulation strategies into situation selection, situation modification, attentional deployment, and cognitive change. Situation selection is the concept of an individual putting himself or herself into a preferred situation or avoiding an aversive one. For example, an 
individual may only attend a party if he or she knows friends who will be there. Once an individual is in a specific situation, that situation can be modified, insofar as the situation allows, in order to change the emotional outcome. Therefore, if an individual finds himself or herself at a party without knowing anyone else there, he or she may try to invite a friend or find someone else at the party who does not know anyone. The component of a situation that an individual decides to attend to is considered attentional deployment and can also change the resulting emotional impact. Thus, the individual may choose to focus on the dog at the party instead of the other people present. Finally, the last antecedent-focused emotion regulation strategy that can be employed is cognitive change, which is the meaning that an individual assigns to the situation. The individual may decide to view this party as a positive opportunity to make new friends. The only response-focused strategy in this model is response modulation which is the process of altering the physiological, experiential, or behavioral emotional responses. This process is also known as expressive suppression. If the individual becomes upset that he or she does not know anyone at the party, he or she may choose to pretend to be having a good time.

Recently, Gross (2015) developed the extended process model of emotion regulation. This extended model incorporates and emphasizes the importance of determining if an emotion is "good" or "bad" for you. This valuation system is similar to the modal model of emotion, beginning with the internal or external world, which triggers an individual's perception of the world. The individual then determines the value of the perception and implements the appropriate mental or physical action. Again, the action can potentially start a feedback loop, restarting the system. From here, there are three stages of emotion regulation: the identification stage (i.e., identifying the emotion that is present), selection stage (i.e., selecting the appropriate emotion regulation strategy), and the implementation stage (i.e., the emotion regulation strategy 
is activated). Depending on the specific emotion regulation strategy used, this extended model can be implicit or explicit (Gross, 2015). Selecting the appropriate emotion regulation strategy is extremely important because while it can lead to successful emotion regulation, it can also lead to failed or maladaptive emotion regulation.

\section{Emotion Regulation Strategy Selection}

Researchers have identified an expansive list of different emotion regulation strategies and have developed multiple theories for why individuals regulate their emotions and why they select one specific strategy over another. Reasons for implementing a specific emotion regulation strategy may be driven by both the motivation behind regulating the emotion and the difficulty of the emotion regulation strategy (Milyavsky et al., 2018; Tamir, 2016). Another possibility may be that our beliefs about emotions, such as whether they are "good" or "bad" and controllable or uncontrollable, determine emotion regulation (Ford \& Gross, 2018). Finally, it could be the orientating attention/action readiness framework (OAAR) that determines which emotion regulation strategy is implemented (Ghafur, Suri, \& Gross, 2018). When an individual has a high level of oriented, or directed, attention, he or she can perform actions quicker. Action readiness, on the other hand, refers to how easy it will be to perform an action, with higher levels making it easier to perform an action (Ghafur et al., 2018). Action readiness is higher for actions that are performed more frequently. Therefore, an individual may be more willing and able to implement a specific emotion regulation strategy if he or she uses it more frequently than other strategies.

Research most often focuses on two specific emotion regulation strategies: reappraisal (i.e., cognitive change) and suppression (i.e., response modulation) (Gross, 1998a; 1999; Gross \& John, 2003; Sakka \& Juslin, 2018). Reappraisal focuses on interpreting a situation in a way that ultimately changes its emotional impact, whereas suppression focuses on hindering 
emotionally-expressive behavior after an emotion has been generated (Gross, 1998a, 1999, 2001;

Gross \& John, 2003; Gross \& Thompson, 2007; John \& Gross, 2004; Milyavsky et al., 2018). Unfortunately, suppression does not always successfully alter emotional experiences in a positive or desired manner.

\section{Reappraisal}

Since reappraisal occurs during the cognitive change stage of the modal model of emotion regulation, it occurs before an emotion is fully experienced and is believed to be a more successful emotion regulation strategy (English et al., 2017; Gross, 1999, 2001, 2002; Gross \& John, 2003; John \& Gross, 2004). Implementing reappraisal results in fewer emotional expressive behaviors, no physiological changes, and decreases self-reported emotional experiences related to negative emotions (Gross, 2002; Gross \& John, 2003; Gross \& Thompson, 2007). Positive emotions are also experienced and expressed to a greater degree when utilizing reappraisal (Gross \& John, 2003). Individuals who use reappraisal more (versus less) frequently are more likely to socially share their emotions, have closer relationships with others, and have better overall well-being (Gross \& John, 2003).

Despite its success as an emotion regulation strategy, reappraisal is not always the emotion strategy that individuals implement. This may be due to emotion intensity, the motivation to decrease the emotional experience, and perceived difficulty of implementing reappraisal (Milyavsky et al., 2018). It may also result from reappraisal being an explicit and controlled emotion regulation strategy, particularly for individuals who believe emotions are uncontrollable (Braunstein et al., 2017; Ford \& Gross, 2018). Individuals are less likely to use reappraisal if the emotion is too intense and they believe reappraising would be too difficult. On the other hand, if the emotion is of a lesser intensity, individuals are then not motivated enough 
to use reappraisal (Milyavsky et al., 2018). Finally, the ability and decision to implement reappraisal may also result from specific environmental experiences (McRae et al., 2017).

\section{Suppression}

Suppression has been shown to be less successful in regulating negative emotions than reappraisal. When experiencing a negative emotion, suppression has only been shown to lessen the emotional expressive behaviors. Suppressing negative emotions actually increases physiological responses and does not impact self-reported emotional experiences at all (Gross, 2002; Gross \& John, 2003; Gross \& Levenson, 1993, 1997). For positive emotions, suppression is successful in decreasing emotional expression and subjective experiences (Gross, 2002; Gross \& John, 2003; Gross \& Levenson, 1997). Individuals who use suppression more are less likely to socially share positive and negative emotions, are more likely to avoid and lack emotional closeness with other individuals, and have overall poorer well-being (Gross \& John, 2003).

Suppression has also been found to be an emotion regulation strategy more commonly used when an individual is in a social situation compared to when an individual is alone. This is true regardless of whether it is a positive or negative emotional experience (English et al., 2017). The reasoning for this may stem from emotional display rules. These rules govern the amount of emotion that is considered socially acceptable to display in different social situations (Ekman \& Friesen, 1969). For example, it is considered more socially acceptable to show sadness and cry at a funeral compared to at the grocery store. Further, individuals are also more likely to use suppression if the emotion regulation goals are instrumental, such as avoiding social conflict and keeping up appearances, when experiencing a negative emotion (English et al., 2017).

Our understanding of emotions has evolved from the idea that physiological responses to objects lead to an emotion, as outlined in the James-Lange Theory (Dewey, 1894, 1895; Irons, 
1894), to the widely accepted and comprehensive modal model of emotions that incorporates a subjective experience, an expressive behavior, and physiological changes (Gross \& Thompson, 2007). Using the modal model of emotions, Gross's (1998b) process model of emotion regulation outlines emotion regulation strategies that can be either antecedent-focused, such as reappraisal, or response-focused, such as suppression (Gross, 2002). Selecting one of these specific emotion regulation strategies can be driven by an individual's motivations for implementing emotion regulation, the difficulty of the emotion regulation strategy, or an individual's emotion regulation goals (Braunstein et al., 2017; Milyavsky et al., 2018; Tamir, 2016). Although it is typically believed that emotion regulation strategies are used to decrease negative emotions and increase positive ones, this is not always the case (e.g., Gross, 1998b; Millgram et al., 2015; Tamir, 2016; van Goethem \& Sloboda, 2011). Nor is it true that each emotion regulation strategy is always successful, and in some cases these strategies may be used maladaptively (Gross, 2002; Gross \& John, 2003; Gross \& Levenson, 1993, 1997). Emotion regulation can be accomplished with different methods, one of which is the use of music.

\section{Music and Emotion Regulation}

\section{Music and Emotion}

Robertson (1934) believed that music can only be described in terms of the musical elements that it contains. He claimed that music is not inherently emotional, rather, emotion is applied to it by the listener. Finally, it is the listener's own emotions and the direction in which the listener wants his or her emotions to go that determines how the music will influence his or her emotions (Robertson, 1934). This is contradictory to many theories that have been, and are still being, applied by researchers examining music and emotion. For example, musical components are believed to have the capacity to cue emotion based on how they are configured 
within a musical piece (Corrigall \& Schellenberg, 2013; Juslin \& Laukka, 2004). Responses to music can be pleasant, unpleasant, excited, relaxed, happy, and sad in nature (Lundin, 1967). Features such as tempo, mode, pitch, rhythm, and timbre all interact in different ways as a method of conveying different emotions (Juslin \& Laukka, 2004; Juslin \& Lindström, 2010; Mursell, 1932; Zhang et al., 2018). In fact, Juslin and Laukka (2004) found that 100\% of participants in their study agreed that music can express emotion, and in response to an openended question asking what music communicates, $47 \%$ answered with responses that were categorized as "emotions." More specifically, music listeners more strongly associate music with slower tempos and minor keys as having negative valence (e.g., sadness), while music with faster tempos and major keys are more strongly associated with positive valence (e.g., happiness; Ramos, Bueno, \& Bigand, 2011; Webster \& Weir, 2005). Fernández-Sotos, FernándezCaballero, and Latorre (2016) also founds that ratings of happiness increased and sadness ratings decreased as musical tempo increased. The Expanded Lens Model of musical communication of emotions outlines the acoustic cues generated from the composer and performer and the interactions between the cues along with the emotional judgement from the listener (Juslin \& Laukka, 2004). Past research has shown that music listeners consistently identify happiness, sadness, fear, anger, and love as the emotions that can be expressed through music (Juslin, 2013; Juslin \& Lindström, 2010). However, there is believed to be a difference between the emotions that can be conveyed by music and the emotions that music can induce in the listener (Juslin, 2013; Juslin \& Laukka, 2004; Juslin \& Lindström, 2010; Robertson, 1934; Zbikowski, 2010). Currently, there are contradictory views concerning music's ability to convey and induce emotions. The first, argued by emotivists, being that music is able to convey and induce genuine emotions in the listener (Levinson, 1990; Sachs et al., 2015). Some researchers believe it may be 
the emotion-specific patterns in music, which are thought to mimic emotional speech, that are responsible for inducing specific emotions in listeners (Juslin \& Laukka, 2004). The emotions believed to be induced in listeners during music listening have been shown to transcend the "basic emotions" of happiness, sadness, fear, anger, and love and include more complex emotions (Juslin, 2013). These emotional experiences are more likely to occur when individuals are listening alone compared to with others and when listeners are already in an emotional state (Juslin \& Laukka, 2004; Randall \& Rickard, 2017).

Hatten (2010) argued that as music listeners, individuals are able to recognize these emotions without always actually experiencing them. Cognitivists take Hatten's (2010) view one step further and claim that listeners can perceive the emotion in music, but music is never able to induce these emotions in the listener (Sachs et al., 2015). Finally, there are those who believe that emotion cannot be inherently conveyed through music. According to Mursell (1971), during music listening an individual's general mood is the most important extrinsic musical component for the listening experience. He believed it was this single factor that reinforces and accompanies all other components that contribute to individual emotional responses during music listening. Further, similar to Robertson's (1934) claims, emotional experiences may be determined by how the listener appraises the music and the motivation behind listening to music in the first place (Juslin \& Laukka, 2004). Listeners are also more likely to experience specific emotions when they select music that they believe evokes certain emotional experiences (Dingle \& Fay, 2017).

Most research examining music and emotion has taken the emotivist view that music is able to convey and induce emotion. Happy and sad music have both been found to induce their respective emotions in listeners, with more individuals feeling sad after listening to the sad music compared to the individuals who feel happy after listening to happy music (White \& Rickard, 
2016). Specifically, self-selected sad music, most frequently that which contains lyrics, has been found to induce sadness more strongly in listeners than unfamiliar sad music. This suggests that lyrical content and the relevance of the musical piece to the listener, such as sad imagery and sad memories that occur during music listening, are important when inducing sadness (Vuoskoski \& Eerola, 2012). However, what occurs when an individual is already in an emotional state and chooses to listen to music as a form of emotion regulation?

\section{Music Listening and Emotion Regulation}

Music listening is an extremely common emotion regulation tactic to implement (Chin \& Rickard, 2014; Randall \& Rickard, 2017; van Goethem \& Sloboda, 2011) and has been found to be one of the most common, and one of the most successful, tactics used to alter a bad mood (Thayer, Newman, \& McClain, 1994). Compared to other media forms, music listening is the most common emotion regulation strategy used in both positive and negative emotional states (Greenwood \& Long, 2009). Lundin (1967) states that “[m]usical responses are delayable and inhibitive...We are able to restrain our musical impulses to play or listen until appropriate times for their expression" (p. 7). The most important reasons for listening to music are for regulating affect and mood and to achieve self-awareness, both of which are considered emotional functions of music listening (Schäfer, Sedlmeier, Städtler, \& Huron, 2013).

Among adolescents, seven strategies have been identified as emotion regulation strategies implemented specifically when listening to music: entertainment, revival, strong sensation, diversion, discharge, mental work, and solace (Saarikallio, 2008). Entertainment occurs when an individual uses music when feeling happy in order to maintain or enhance that feeling by creating a happy atmosphere. Revival involves reenergizing through music listening when feeling tired or stressed. Strong sensation occurs when an individual listens to music in order to have an 
intense emotional experience. Diversion involves listening to pleasant music in order to forget unpleasant feelings. The goal of discharge is to listen to music that expresses feelings of anger or sadness. Mental work incorporates music listening in order to assist with reappraisal and interpretation of a situation to change the emotional response. Finally, solace involves listening to music that provides acceptance and understanding when experiencing sad emotions (Saarikallio, 2008). These specific emotion regulation strategies, however, do not always determine which types of music an individual specifically chooses to listen to.

Perhaps our decision to listen to specific types of music is driven by the reason we are choosing to listen to music in the first place (Schäfer et al., 2013; van Goethem \& Sloboda, 2011). Individuals who are already in a sad emotional state have been found to select music identified as sad and slow compared to individuals who are not in a sad emotional state (Friedman, Gordis, \& Förster, 2012). van Goethem and Sloboda (2011) identified musical features (e.g., emotion, type, familiarity, and content) as the most common reason for selecting music to help with specific emotion regulation strategies. Different emotion regulation strategies have been found to be linked with different music listening habits. Individuals who listen to heavy metal, alternative rock, hip-hop and rap, punk, and rave have a tendency of using music for emotion regulation more than for individuals who do not listen to music in these genres (Bodner \& Bensimon, 2014). More specifically, individuals who listen to this music tend to do so because they believe it revives positive emotions, diverts or discharges negative emotions, acquires new experiential perspectives through mental work, and encourages solace (Bodner \& Bensimon, 2014). Suppression has been most commonly used by individuals who listen to music more intensely, who engage in musical production, and who listen to music to connect with 
others. Further, individuals who use music for reappraisal consistently have better well-being than those who use music for suppression (Chin \& Rickard, 2014).

Emotional change from music listening is largely dependent on the listener's initial emotional state (Randall \& Rickard, 2017). Individuals seeking to use music for emotion regulation are almost twice as likely to use music as an emotional response-focused strategy instead of an antecedent-focused strategy. This may be because emotion regulation strategies that require greater cognitive processes, such as reappraisal, become more difficult and less successful as emotional intensity and valence increase (Randall, Rickard, \& Vella-Brodrick, 2014). Listening to music as a form of distraction, suppression, and enhancement has been found to improve a negative emotional state if the listener was in one prior to music listening (Randall et al., 2014). Discharge and solace have specifically been found to be implemented more often when the emotion of the music is congruent with the emotion the individual is feeling at the time (Saarikallio, Nieminen, \& Brattico, 2012). In addition, individuals who are already experiencing "bad" emotions when choosing to listen to music have been found to experience greater mood improvements if they listen to happy music compared to sad music (Randall \& Rickard, 2017; Shifriss et al., 2015; Zavoyskiy et al., 2016). However, if this is the case, why do so many individuals still choose to listen to sad music when they are experiencing "bad" emotions instead of happy music?

Jerrold Levinson argued that there are eight benefits of listening to sad music, and that these benefits occur because sad music is able to induce sadness in the listener (Levinson, 1990). Levinson outlined these eight benefits as: catharsis, expressing negative emotions; apprehending expression, understanding the emotions in the music; savoring feeling, the satisfying feeling that results from experiencing any emotional response from the music; understanding feeling, 
understanding one's own feelings; emotional assurance, verifying one's own capability of experiencing deep emotions; emotional resolution, knowing an emotion can be regulated; expressive potency, the positive feelings that result from emotional expression; and emotional communion, connecting emotionally to the emotions of the artist or other listeners (Levinson, 1990). These benefits only show why individuals find pleasure in listening to sad music, they do not imply that they are used to regulate emotions or that they are even used in a sad emotional state.

Although music is generally used as an emotion regulation strategy in order to enhance positive emotions or reduce negative emotions, some individuals use music as a way to enhance their negative emotions (Garrido \& Schubert, 2013; Randall \& Rickard, 2017; Sakka \& Juslin, 2018; van Goethem \& Sloboda, 2011). The goal of using music to enhance negative emotions is used less frequently than enhancing positive emotions and reducing negative emotions but still occurs nonetheless (Sakka \& Juslin, 2018). If individuals listen to music specifically for emotional reasons when alone and already in a negative emotional state, individuals may find enjoyment in maintaining this negative emotional state (Randall \& Rickard, 2017). Finally, individuals may need to enhance their current negative emotions in order to understand them better before being able to regulate them effectively (van Goethem \& Sloboda, 2011). Others may listen to sad music, not necessarily to enhance their negative emotions, but simply as a way to reflect and process their sadness (Garrido \& Schubert, 2011, 2013; Stapley, 2014). Reflectiveness has been found to be positively correlated with the enjoyment of sad music (Garrido \& Schubert, 2013). Individuals who are more likely to ruminate tend to be attracted to sad music because it provides catharsis and is relatable, not because they actually enjoy sad music (Garrido \& Schubert, 2013). This idea that sad music is relatable is similar to one of 
Levinson's (1990) benefits of listening to sad music: emotional communion (Garrido \& Schubert, 2011). The ability to connect to the emotions of the artist or other listener may provide a sense of emotional support. However, even individuals who do not have a tendency to ruminate opt to listen to sad music because it is cathartic (Garrido \& Schubert, 2011). Finally, the moodcongruency principle states that an individual's current mood elicits self-relevant cognitions and self-directed behaviors of the same valence (Sedikides, 1992). Recent research examining emotional experience and music choice has supported this principle. Individuals who are in a sad emotional state more often choose to listen to sad music than happier music compared to individuals who are not in a sad emotional state (Chen et al., 2007; Hunter et al., 2011; Lee et al., 2013; Randall \& Rickard, 2017; Taruffi \& Koelsch, 2014; except O’Malley et al., 2016).

Friedman et al. (2012) and Taylor and Friedman (2015) found that this is driven, at least in part, by the belief that listening to happy music when feeling sad would be inappropriate and would not help with mood repair. Further, individuals who listen to music that is of the same emotional valence as the emotions that they are experiencing tend to listen to music in order to regulate their emotions in their everyday lives (Saarikallio et al., 2012).

\section{Purpose of the Present Study}

From this literature, I have identified four potential emotion regulation strategies someone might choose to use when listening to sad music when feeling sad. First, it can provide catharsis, a way for listeners to express or release the sadness that they are feeling (Garrido \& Schubert, 2011, 2013; Levinson, 1990; Norton, 2011). Second, it can provide emotional support. Similar to Levinson's (1990) concept of emotional communion, sad music may provide listeners with support knowing that other people may feel the same way as them. Third, listening to sad music may help individuals understand their own sadness (van Goethem \& Sloboda, 2011). 
Listeners may do this by reflecting on and processing their emotions (Garrido \& Schubert, 2013; Stapley, 2014). Finally, individuals may opt to listen to sad music when experiencing sadness for the purposes of mood congruency. Individuals often partake in behaviors that match the valence of the emotions they are experiencing at that time (Sedikides, 1992). This is partially due to individuals feeling as though it would be inappropriate to listen to happy music when they are feeling sad and that happy music would not help improve their mood (Friedman et al., 2012; Taylor \& Friedman, 2015).

The emotion regulation strategies of catharsis, emotional support, understanding emotions, and mood congruency are assumed to incorporate the use of sad music. However, this has not been tested experimentally. Thus, this study will confirm that the participants using these strategies when feeling sad do select music that is also "sad," meaning it will be in a minor key and have fewer beats per minute, and will also be rated as more sad and slow by external raters (Ramos et al., 2011; Webster \& Weir, 2005). In order to make these confirmations about these four emotion regulation strategies, they will be compared to revival. Revival is typically viewed as an emotion regulation strategy that involves listening to happy music with the goal of relaxing or regaining energy (Saarikallio, 2008, 2012; Shifriss et al., 2015). Since revival incorporates listening to happy music, participants using this strategy should also select music that is in a major key, have more beats per minute, and be rated as happier and faster by external raters (Ramos et al., 2011; Webster \& Weir, 2005).

In order to meet these goals, college students were recruited to participate in an experimental study. A sad film clip was used to induce sadness in participants. Participants were then be randomly assigned to choose a song to listen to by using one of the five emotion regulation conditions (i.e., catharsis, emotional support, understanding emotions, mood 
congruency, or revival). The success of the sadness induction procedure was determined by changes in participant reported sadness. Participants' satisfaction with the song they chose to listen to was used to determine the success or failure of each emotion regulation strategy. In addition, a manipulation check was implemented to confirm that participants in each emotion regulation condition selected music based on the instructions they were given. To further confirm the reasons why participants selected the songs they did, they rated the extent to which they used each emotion regulation strategy and provided an open-ended response for why they selected the song. Finally, to determine whether or not the songs selected by participants are considered "sad," these songs were recorded in order to identify their keys and beats per minute.

\section{Hypotheses}

Since this study focused on emotion regulation strategies implemented by individuals when they are experiencing sadness, as a manipulation check, I anticipated participants would successfully identify the instructions they were given when selecting a song to listen to. As a confirmation, I believed participants would also rate those instructions as playing into their decision to select their specific song to a greater extent than the others. Exploratory qualitative analysis were conducted to identify overarching themes across participant song choice explanations.

Additionally, in order to identify catharsis, emotional support, understanding emotions, and mood congruency as the emotion regulation strategies that use sad music and are implemented when in a sad emotional state, I established five different, but related, hypotheses. Initially, I expected that participants in each of the five experimental conditions would have similar preferences for how they use music for emotion regulation based on their scores on the Brief Music in Mood Regulation Scale (Saarikallio, 2008). I also hypothesized that using a sad 
movie clip would successfully induce sadness in the participants (e.g., Kahn, Cox, Bakker, O’Loughlin, \& Kotlarczyk, 2017; Kahn et al., 2019). Since some participants may have selected music that enhanced their sadness, maintained their sadness, or provided relief, it was not clear how each of the emotion regulation strategies would impact participant sadness after listening to music. Therefore, I examined this in an exploratory manner. Third, prior to the manipulation, I expected participants to rate catharsis, emotional support, understanding emotions, and mood congruency, compared to other non-emotion regulation reasons, as the four that they are most likely to use when choosing to listen to sad music when they are already feeling sad. Fourth, I hypothesized that participants who were assigned to these four conditions would experience greater satisfaction with their song choices after listening to them compared to participants in the revival condition. Fifth, I predicted the songs selected by participants in these four conditions would have fewer beats per minute (BPM) and they would more often be in a minor key than the songs selected by participants in the revival condition, which would have a greater BPM and more often be in a major key. I also anticipated that these songs (compared to songs from the revival condition) would be rated as sadder, less arousing and calmer, and slower by external raters. Finally, those songs selected using revival would be rated as happier, less calm and more arousing, and faster by external raters compared to songs selected using the other four emotion regulation strategies. 


\section{CHAPTER III: METHODOLOGY}

\section{Participants}

Based on a power analysis for a one-way ANOVA using a medium to large effect size of 0.32 (which was determined a priori), a sample of 125 participants distributed evenly across five groups would provide power at 0.80 . Participants consisted of 134 current undergraduate and graduate students at Illinois State University. Data from one participant was excluded because the researcher determined this individual did not properly follow the instructions provided and did not actively watch the film clip. An additional 11 participants were excluded because they answered the first forced-choice manipulation check question incorrectly. Therefore, the final sample size utilized for analyses was 122 participants whose ages ranged from 18 to 25 ( $M=$ $19.43, S D=1.49)$. Of these 122 participants, 105 stated that they identified as female, 15 as male, and 2 as another gender (e.g., gender fluid, transgender, etc.). Eighty-five participants stated that they were Caucasian or European American, 16 were African American, 12 were Latina or Latino, 4 were biracial or multiracial, 2 were Asian American or of Asian descent, 1 was of Middle Eastern descent, and 1 identified as another race/ethnicity/cultural background. Finally, 46 participants were freshmen, 28 were sophomores, 23 were juniors, 24 were seniors, and 1 was a graduate student.

In order to participate, individuals had to have been at least 18 years of age. Otherwise, no specific age, race/ethnicity, gender, or field of study was targeted. There were no other inclusion or exclusion criteria. Participants were recruited using Illinois State University's Sona system. In exchange for their participation, participants were offered extra credit points. 


\section{Materials}

\section{Film Stimulus}

A single, 11-min clip from the film Marley \& Me (2008) was utilized in order to induce sadness in all participants. During this film segment, the father of a family takes the family's pet dog to the veterinarian, and the dog ultimately needs to be euthanized. The film switches between the dog's euthanization and the father's son who is watching an old home video of the family with their dog. This same clip has been used in previous research to successfully induce sadness (Kahn et al., 2017, 2019, for example).

\section{Song Selection}

Spotify Premium was used for the purposes of music song selection and for music listening. Spotify is a music streaming service that offers an extensive variety of song choices across genres, artists, and time periods. Using Spotify also allowed only the audio to be played during the song without any visual stimuli (e.g., a music video), preventing the possibility of visual stimuli confounding the results. The Premium version of Spotify allowed participants to select any single song they wished to listen to without having to shuffle the songs in a playlist and without having to listen to any ads. Again, this prevented the possibility of other auditory stimuli confounding the results.

In order to examine song emotionality, Tunebat was used to determine the key and beats per minute (BPM) for each song selected by participants. Tunebat is an online database that allows users to search by song, artist, or album and provides users with song information including song key, BPM, duration, and more. Tunebat is also a Spotify Web API, meaning it retrieves information, including song data, from Spotify's database. This made it extremely likely that all songs available for streaming through Spotify, and thus any songs that participants 
were able to listen to during the experimental procedure, would have key and BPM data available through Tunebat. As a means to determine the validity of the information available in Tunebat, BPMKey was used to cross-check the key and BMP of each song. BPMKey is another online database that allows users to search by song, artist, or album and provides users with song information including song key and BPM. In the event that a participant's song choice was not included in Tunebat's database or the song's key and BPM in Tunebat did not match that in BPMKey, his or her song data was excluded from analyses.

After all participants completed the study, the songs that participants chose to listen to were compiled into a single list with the order randomized. This list was given to three raters; these raters were also researchers involved in data collection. Two of these the raters were given the complete list of songs, one was instructed to identify the key and BPM of each song using Tunebat, and the other was instructed to identify the key and BPM of each song using BPMKey. The third rater was only given half of the songs and was instructed to identify the key and BPM of each song using both Tunebat and BPMKey.

\section{Measures}

\section{Demographic Information}

Using the Demographic Information Questionnaire, information was gathered about participant gender, race/ethnicity, education, and age (see Appendix A).

\section{Sadness}

The Positive and Negative Affect Schedule - Expanded Form (PANAS-X; Watson \& Clark, 1994) is a 60-item self-report measure composed of 13 subscales. Each item is rated on a 5-point Likert scale $(1=$ very slightly or not at all to $5=$ extremely $)$. It can be administered with

the instructions altered to have participants rate how they are feeling "right now," "today," 
"during the past few days," "during the past week," "during the past few weeks," "during the past month," "during the past year," or "in general." The PANAS-X scales have been shown to be sensitive to emotional fluctuations when using instructions that target short-term time frames, such as "right now" and "today." For the purposes of this study, participants were provided with instructions to rate how they are feeling "right now," and only the Sadness subscale (5 items) was used in order to specifically measure participant sadness. Scores from the sadness subscale have an alpha coefficient of .86 when using the "right now" instructions (Watson \& Clark, 1994).

\section{Emotion Regulation and Music}

The Brief Music in Mood Regulation Scale (B-MMR; Saarikallio, 2012) is a 21-item self-report measure that identifies the emotion regulation strategies that are implemented during music listening. It is composed of seven subscales: Entertainment $(\alpha=.81)$, Revival $(\alpha=.80)$, Strong Sensation $(\alpha=.81)$, Diversion $(\alpha=.73)$, Discharge $(\alpha=.84)$, Mental Work $(\alpha=.84)$, and Solace $(\alpha=.85$; Saarikallio, 2012). Each subscale is comprised of three questions rated on a 5point Likert scale $(1=$ Strongly Disagree to $5=$ Strongly Agree $)$. For the purposes of this study, the B-MMR was modified to add a Mood Congruency subscale as well as a second Discharge subscale that contained items specifically targeting sadness instead of anger (see Appendix B). Based on the results from this study, the alpha coefficients for these two subscales were $\alpha=.61$ and $\alpha=.85$, respectively. The modified version contains 28 items that were still rated on the same 5-point Likert scale.

\section{Typical Music Choice}

The Reasons for Listening to Sad Music Questionnaire was developed for this study in order to gather information on why participants typically choose to listen to sad music when in a 
sad emotional state. Participants were given a list of nine reasons for why they may choose to listen to a sad song when they are already feeling sad. Five of these reasons matched the five experimental conditions (i.e., catharsis, emotional support, understanding emotions, mood congruency, and revival) and the other four reasons acted as filler reasons. Participants were asked to rate each of the nine reasons on a 5-point Likert scale as a reflection of how likely they are to select a sad song based on each item $(1=$ not at all likely to $5=$ extremely likely). This measure was used to confirm catharsis, emotional support, understanding emotions, and mood congruency as the four emotion regulation strategies that are most likely to be implemented when individuals in a sad emotional state select sad music to listen to (see Appendix C).

\section{Song Satisfaction}

The Song Satisfaction Scale was developed for the purposes of this study in order to measure each participant's satisfaction with their song choice after having the opportunity to listen to it. This survey is composed of 4 items $(\alpha=.79)$. Participants used a 4-point Likert scale $(1=$ Strongly Disagree to $4=$ Strongly Agree $)$ to indicate the degree to which they agreed or disagreed with each statement. Higher scores indicated greater satisfaction with song choice (see Appendix D).

\section{Experimental Song Selection}

The Song Selection Survey was also developed for this study to identify the extent to which participants selected music for catharsis, emotional support, understanding their emotions, mood congruency, and revival. Participants were first presented with an item asking them to select the one option that matched the instructions they were given for how to select a song to listen to. Each of the five options matched the instructions of each of the five experimental conditions. This acted as a manipulation check to ensure that participants selected a song based 
on the instructions they were given in their assigned condition. This same item was used before song selection and again after song selection. For confirmatory purposes, participants were then instructed to rate the extent to which each of these five options played into their own decision to select the specific song that they did using a 5-point Likert scale $(1=$ Not at all to $5=$ Extremely; see Appendix E).

Finally, as another confirmation, participants were presented with an open-ended question asking them to explain why they chose the song that they did. Qualitative data analysis methods were used in order to analyze the open-ended question asking participants to provide additional explanation for why they selected the song that they did. Two participants did not provide responses to this question and had to be excluded from the qualitative analysis. Three raters who were not blind to the study's purpose (i.e., undergraduate students who assisted with data collection and compiled Tunebat and BPMKey data) were given the open-ended responses in a randomized order. However, in order to prevent the knowledge of which response was associated with other study variables and results, each response was given a random ID that was different from the participant's original ID number. No other data were provided with the openended responses. The raters then read through all responses and independently identified general themes to which they assigned each response.

After they independently completed this process, a professor of psychology asked the raters to identify which themes had the largest numbers of responses associated with them and moderated the discussion. Common themes across the three raters were identified, and discussions determined whether or not the themes would have sufficient participant responses associated with them. Based on agreement between the three raters, certain themes were consolidated, broken apart, and further defined. If any rater was unsure about the practicality of 
multiple themes being grouped together, the themes remained separate from one another. The same rule applied to any themes that may have been broken apart. After consensus was reached for the themes that would be used, the raters individually re-categorized the participant responses according to these new themes. Raters identified nine themes under which all participant responses were believed to fall: cheering up, feel/understand emotions, brings back a memory, connecting to a mood/matches emotions, connecting to the movie, support from music, fan of the artist/song, tone/beat of the song, and miscellaneous/other.

\section{External Song Rating}

The Song Rating Scales were specifically developed for this study to allow external raters blind to this study's purpose to rate the emotionality of the songs selected by participants. The participant song list order was randomized for each external rater, and if the same song was chosen by multiple participants it was only listed once in the song list. Raters were asked to listen to each song on Spotify in its entirety. They did so in a private laboratory setting free of any other distractions and independently of the other raters. Raters were instructed to only listen to songs in 30-min blocks and to take breaks after 30 min to prevent exhaustion. After listening to each song, they completed the Song Rating Scales. Three raters were asked to rate each song's emotionality based on four emotions (happiness, sadness, anger, and fear), how arousing each song was, the song's speed, and the song's familiarity to the rater. However, only happiness, sadness, calming, arousing and speed were analyzed as part of my hypotheses with familiarity used as a covariate. Each item (except for speed) was rated on the same 5-point Likert scale $(1=$ Not at all to $5=$ Extremely). The item asking raters to identify the speed of the song used a slightly different 5-point Likert scale (1 = Very Slow to 5 = Very Fast; see Appendix F). Each rater only listened to two-thirds of the songs selected by participants, where each song was 
evaluated by two out of the three external raters. Therefore, reliability was calculated for each item by averaging the intraclass correlations between all three pairs of raters: happiness (.62), sadness (.77), anger (.45), fear (.28), arousing (.37), calming (.49), speed (.80), and familiarity (.53). Acceptable interrater reliability is usually considered to be .80 or higher (Heiman, 2001). With this in mind, reliability is problematic for many of these measures as they do not reach this .80 minimum.

\section{Procedure}

The study took place in a laboratory setting. Prior to their arrival, participants were randomly assigned to one of five experimental conditions: catharsis, emotional support, understanding emotions, mood congruency, or revival. Immediately upon their arrival, participants were given the informed consent form to read and sign if they agreed to participate. Afterwards, participants completed the Demographic Information Questionnaire. They were then given the modified version of the Brief Music in Mood Regulation Scale (B-MMR) in order to determine their typical emotion regulation strategies based on how they use music. Participants also completed the Reasons for Listening to Sad Music Questionnaire. They then completed the PANAS-X Sadness subscale to determine their initial sadness before sadness was induced.

In order to most effectively induce a sad emotional state, participants watched an 11-min clip from the movie Marley \& Me. The participants were instructed that the experimenter would step out of the room during this clip. Participants were told that they would be using headphones while watching this clip, to remove the headphones once the movie clip was over, and to open the door to notify the experimenter when the clip had ended. The end of the film clip also had a written reminder for the participants to get the experimenter. The experimenter then asked the participants to put on the headphones, started the film clip, and exited the room. After the 
participant notified the experimenter that the film clip had ended, the experimenter re-entered the room and closed the movie clip window to prevent it from unintentionally playing during the rest of the experiment. Participants were then given the PANAS-X Sadness subscale again as a way for the participants to rate their current feelings of sadness in response to the movie clip. Since the subscale is only 5 items, I believed that completing this measure at this time would not impact the intensity of the sadness participants were feeling.

After completion, the experimenter then read the instructions for picking out a single song to listen to. The instructions were also provided to participants on a sheet of paper with the first line of the instructions highlighted for emphasis:

I would now like you to select a single song to listen to that allows you to express the emotions you are feeling. It is very important that you select a song with this in mind. Please repeat back to me your instructions for a selecting a song to listen to. You may use the highlighted portion of the printed instructions on the index card for your reference. (catharsis)

The first line of the instructions was determined by the participant's randomly assigned experimental condition: "I would now like you to select a single song to listen to that provides you with emotional support." (emotional support); "I would now like you to select a single song to listen to that allows you to better understand the emotions you are feeling." (understanding emotions); "I would now like you to select a single song to listen to that matches the emotions you are feeling." (mood congruency); "I would now like you to select a single song to listen to that will cheer you up." (revival). If the participant did not repeat the instructions back correctly, the researcher repeated this process up to two more times, if necessary, before moving on. The researcher recorded the number of incorrect responses and whether or not the participant 
provided a correct response. After this process, the remainder of the instructions were the same across all conditions:

Please select a song that is no longer than 6 minutes in length. Choose carefully as you will only have the opportunity to listen to one song once it begins. Once you identify the song you would like to listen to, put your headphones on and press play. You can then adjust the volume to a level that is comfortable for you. Please listen to the song in its entirety. Once the song is over, press pause to stop another song from playing and remove your headphones.

Participants then answered an additional question asking them to, once again, identify the instructions they were given when deciding on which song to listen to. Afterwards, the experimenter opened Spotify so the participants could select the song of their choice and listen to their selection. During this time, the experimenter recorded the song title, song artist, and song album.

At the song's conclusion, Spotify was minimized from view, and participants completed the Song Satisfaction Scale to determine how satisfied they were with their song selection. They completed the Song Selection Survey and then were presented with a blank text box with instructions asking them to further explain why they chose to listen to that specific song. The participants were given the following instructions: "Your next task is to provide additional explanation for why you chose to listen to that specific song. Do not type your name anywhere in your response. Please be concise as your response will be limited to 280 characters." For a third and final time, participants were given the PANAS-X Sadness subscale to complete, and afterwards they were debriefed and dismissed. 


\section{CHAPTER IV: RESULTS}

\section{Manipulation Checks}

Prior to the exclusion of 11 participants who incorrectly answered the first manipulation check, 27 participants were in the catharsis condition, 27 were in the emotional support condition, 27 were in the understanding emotions condition, 26 were in the mood congruency condition, and 26 were in the revival condition. A chi-square test of independence was conducted using experimental condition and responses to the first closed-ended question asking participants to identify the instructions they were given when selecting a song to listen to. Results indicated a significant association between experimental condition and instruction selection, $\chi_{2}(16, N=133)$ $=433.66, p<.001$ (see Table 1 ). This was the only analysis conducted with the 11 participants who incorrectly answered this first manipulation check in order to show that the manipulation was still successful as was hypothesized. All other reported results exclude these participants, as was decided a priori, because they may not have selected a song based on the instructions they were given.

After the removal of the 11 participants who incorrectly responded to this manipulation check, 21 participants were in the catharsis condition, 27 were in the emotional support condition, 23 were in the understanding emotions condition, 25 were in the mood congruency condition, and 26 were in the revival condition. A second chi-square test of independence was conducted using experimental condition and responses to the second close-ended question asking participants to identify the instructions they were given when selecting a song to listen to. Results indicated a significant association between experimental condition and instruction selection, $\chi_{2}(16, N=122)=468.48, p<.001($ see Table 2$)$. 


\section{Table 1}

First Manipulation Check Using Response Frequencies for Each Set of Song Selection Instructions According to Experimental Condition

\begin{tabular}{|c|c|c|c|c|c|}
\hline \multirow[b]{2}{*}{ Song Selection Instructions } & \multicolumn{5}{|c|}{ Experimental Condition } \\
\hline & Catharsis & $\begin{array}{l}\text { Emotional } \\
\text { Support }\end{array}$ & $\begin{array}{l}\text { Understanding } \\
\text { Emotions }\end{array}$ & $\begin{array}{c}\text { Mood } \\
\text { Congruency }\end{array}$ & Revival \\
\hline $\begin{array}{l}\text { Select a single song to listen to that allows you to } \\
\text { express the emotions you are feeling. (Catharsis) }\end{array}$ & 21 & 0 & 3 & 1 & 0 \\
\hline $\begin{array}{l}\text { Select a single song to listen to that provides you with } \\
\text { emotional support. (Emotional Support) }\end{array}$ & 3 & 27 & 0 & 0 & 0 \\
\hline $\begin{array}{l}\text { Select a single song to listen to that allows you to } \\
\text { better understand the emotions you are feeling. } \\
\text { (Understanding Emotions) }\end{array}$ & 0 & 0 & 23 & 0 & 0 \\
\hline $\begin{array}{l}\text { Select a single song to listen to that matches the } \\
\text { emotions you are feeling. (Mood Congruency) }\end{array}$ & 2 & 0 & 1 & 25 & 0 \\
\hline $\begin{array}{l}\text { Select a single song to listen to that will cheer you up. } \\
\text { (Revival) }\end{array}$ & 1 & 0 & 0 & 0 & 26 \\
\hline
\end{tabular}




\section{Table 2}

Second Manipulation Check Using Response Frequencies for Each Set of Song Selection Instructions According to Experimental Condition

\begin{tabular}{|c|c|c|c|c|c|}
\hline \multirow[b]{2}{*}{ Song Selection Instructions } & \multicolumn{5}{|c|}{ Experimental Condition } \\
\hline & Catharsis & $\begin{array}{l}\text { Emotional } \\
\text { Support }\end{array}$ & $\begin{array}{l}\text { Understanding } \\
\text { Emotions }\end{array}$ & $\begin{array}{c}\text { Mood } \\
\text { Congruency }\end{array}$ & Revival \\
\hline $\begin{array}{l}\text { Select a single song to listen to that allows you to } \\
\text { express the emotions you are feeling. (Catharsis) }\end{array}$ & 21 & 0 & 0 & 2 & 0 \\
\hline $\begin{array}{l}\text { Select a single song to listen to that provides you with } \\
\text { emotional support. (Emotional Support) }\end{array}$ & 0 & 27 & 0 & 0 & 0 \\
\hline $\begin{array}{l}\text { Select a single song to listen to that allows you to } \\
\text { better understand the emotions you are feeling. } \\
\text { (Understanding Emotions) }\end{array}$ & 0 & 0 & 23 & 0 & 0 \\
\hline $\begin{array}{l}\text { Select a single song to listen to that matches the } \\
\text { emotions you are feeling. (Mood Congruency) }\end{array}$ & 0 & 0 & 0 & 23 & 0 \\
\hline $\begin{array}{l}\text { Select a single song to listen to that will cheer you up. } \\
\text { (Revival) }\end{array}$ & 0 & 0 & 0 & 0 & 26 \\
\hline
\end{tabular}


To confirm the success of the manipulation checks, five separate one-way ANOVAs were conducted using the individual instructions from the second portion of the Song Selection Survey (see Figure 1). As the ANOVAs and post hoc tests reveal below, the hypothesis that participants would rate the instructions for their condition as playing into their decision to select their specific song to a greater extent than the others was only partially supported. Scheffe post hoc tests were used because they are very conservative and are less likely to result in Type I errors (Heiman, 2001). In the past, Scheffe has also been considered the most widely accepted post hoc test (Shavelson, 1996). Bonferroni corrections were used in later analyses when Scheffe was unavailable in SPSS as they are also less likely to result in Type I errors (Field, 2013).

\section{Catharsis}

Participants in the different experimental conditions rated the instructions given to participants in the catharsis condition as playing into their music selection decision significantly differently, $F(4,117)=5.55, p<.001$, partial $\eta^{2}=.16$. Scheffe post hoc tests revealed that participants in the catharsis condition only rated the catharsis instructions as playing into their music selection decision to a greater extent than the participants in the revival condition, $p=$ .015 . There were no significant differences between participants in the catharsis condition and participants in the other conditions.

\section{Emotional Support}

Participants also rated the instructions given to participants in the emotional support condition as playing into their music selection decision significantly differently, $F(4,117)=$ $9.20, p<.001$, partial $\eta_{2}=.24$. Scheffe post hoc tests revealed that participants in the emotional support condition rated their instructions as playing into their music selection decision to a 
greater extent than participants in the catharsis $(p=.011)$, mood congruency $(p<.001)$, and revival $(p<.001)$ conditions, but not the understanding emotions condition $(p=.282)$.

\section{Understanding Emotions}

Similarly, participants in the different conditions rated the understanding emotions instructions as playing into their music selection decision significantly differently, $F(4,117)=$ 7.97, $p<.001$, partial $\eta_{2}=.21$. Scheffe post hoc tests indicated that participants in the understanding emotions condition rated their instructions as playing into their music selection decision to a greater extent than participants in the emotional support $(p=.036)$ and revival $(p<$ $.001)$ conditions, but not the catharsis $(p=.242)$ or mood congruency $(p=.210)$ conditions.

\section{Mood Congruency}

The mood congruency instructions played into the music selection decisions for participants in the separate conditions significantly differently, $F(4,117)=22.69, p<.001$, partial $\eta_{2}=.44$. The Scheffe post hoc tests showed mood congruency participants rated their instructions as playing into their song selection decision to a greater extent than only participants in the emotional support $(p<.001)$ and revival $(p<.001)$ conditions.

\section{Revival}

Finally, the revival instructions played into the music selection decisions for participants in the separate conditions significantly differently, $F(4,117)=14.81, p<.001$, partial $\eta_{2}=.34$. The final Scheffe post hoc tests showed participants in the revival condition rated their instructions as playing into their song selection decision to a greater extent than participants in the catharsis, understanding emotions, and mood congruency conditions (all $p s<.001$ ), but not the emotional support condition $(p=.123)$. 


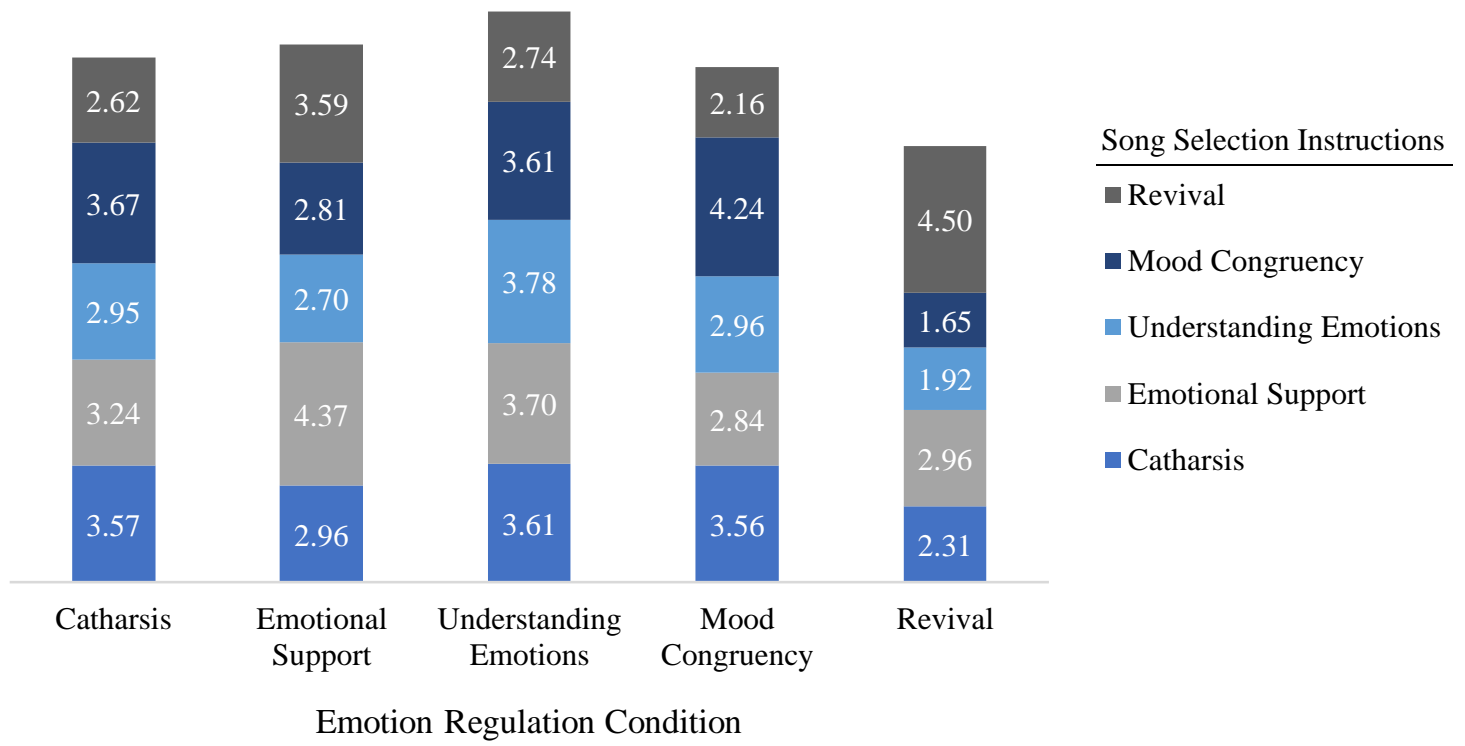

Figure 1. Average ratings for how each set of song selection instructions played into the music selection decisions for participants in the different experimental conditions.

\section{Qualitative Data Analysis}

Participants were asked to provide an additional, free-response explanation for why they chose the specific song to listen to that they did. This was done to provide additional clarity as to whether or not the manipulation check was successful and to shed light onto the other reasons why participants chose these specific songs when they were feeling sad. I compiled all of the categorized responses from the three raters, and I decided that each response would only fall under one of the defined categories. If there was a discrepancy among the three raters where only two out of the three agreed, the participant response would be categorized under the category agreed upon by the two raters. If a participant response was identified as falling under three difference categories by the three different raters, I chose which of the three categories the response best fit. This decision was made blind of the condition the participant had been in to reduce the potential for this to bias my decision. There were two participants who did not 
provide a response and could not be included in the qualitative results. Overall, 19 participants provided responses categorized under cheering up, 15 under feel/understand emotions, 22 under brings back a memory, 14 under connecting to a mood/matching emotions, 13 under connecting to the movie, 10 under support from music, 12 under fan of the artist/song, 11 under tone/beat of the song, and 4 under miscellaneous/other. The frequency of responses in each category broken down by experimental condition can be found in Table 3 . 
Table 3

Frequencies of Participant Responses for Each Qualitative Response Category by Experimental Condition

\begin{tabular}{|c|c|c|c|c|c|}
\hline \multirow[b]{2}{*}{ Qualitative Response Category } & \multicolumn{5}{|c|}{ Experimental Condition } \\
\hline & Catharsis & $\begin{array}{l}\text { Emotional } \\
\text { Support }\end{array}$ & $\begin{array}{l}\text { Understanding } \\
\text { Emotions }\end{array}$ & $\begin{array}{c}\text { Mood } \\
\text { Congruency }\end{array}$ & Revival \\
\hline Cheering Up & 0 & 4 & 4 & 0 & 11 \\
\hline Feel/Understand Emotions & 4 & 4 & 6 & 1 & 0 \\
\hline Brings Back a Memory & 2 & 6 & 0 & 3 & 11 \\
\hline Connecting to a Mood/Matches Emotions & 1 & 2 & 4 & 7 & 0 \\
\hline Connecting to the Movie & 2 & 3 & 3 & 5 & 0 \\
\hline Support from Music & 2 & 7 & 0 & 1 & 0 \\
\hline Fan of the Artist/Song & 4 & 1 & 1 & 4 & 2 \\
\hline Tone/Beat of the Song & 6 & 0 & 3 & 1 & 1 \\
\hline Miscellaneous/Other & 0 & 0 & 1 & 2 & 1 \\
\hline
\end{tabular}


Despite the generally smaller cell sizes, there still appears to be a pattern between how participant responses were categorized and which condition the participants were in. For example, the cheering up category had the most responses from participants in the revival condition; this included responses such as "I chose this song because I knew it would cheer me up and make me feel like dancing. This song helped." One response that appeared in the feel/understand emotions category was "I chose a song that allowed me to better understand the emotions I felt after watching the sad movie clip. I chose a song that wasn't too sad, however. It was sad but was still fulfilling in a way to help me understand my emotions." Most of the responses in this category were provided by those participants in the understand emotions condition. This same pattern was true for the connecting to a mood/matches emotions category which had the most responses (such as "I chose this song because it was a calm and sort of sad song which is what I was feeling at the time when I chose that song") from participants in the mood congruency condition. It was also true for the support-from-music category which participants in the emotional support condition provided the most responses for (including "I chose this song because in the past it has given me emotional support"). Participants in the catharsis condition had the most responses categorized under tone/beat of the song (e.g., "I like the beat of the song and the meaning as well. I personally think it is kind of a sad song, which helped me express my depressed feelings after watching a dog die"). Catharsis was the only condition that did not have a category that was comparable to its meaning. However, like this example suggests, explanations from participants in the catharsis condition may have had the opportunity to fall under multiple categories, but statements of song tone/beat may have overshadowed those about emotional expression. 


\section{Emotion Regulation Preferences}

In order to determine whether or not participants in each of the experimental conditions had similar preferences for how they typically regulate their emotions using music in general prior to the start of the experiment, a MANOVA was used with emotion regulation condition as the independent variable and the nine B-MMR subscale scores as the dependent variables. This analysis revealed no significant differences for participants in the different conditions, Wilks' $\Lambda=.70, F(36,387.73)=1.09, p=.333$, partial $\eta_{2}=.09$ (see Figure 2$)$. This supports the hypothesis that, prior to the start of the experiment, participants in each condition would have similar preferences for how they typically use music for emotion regulation.

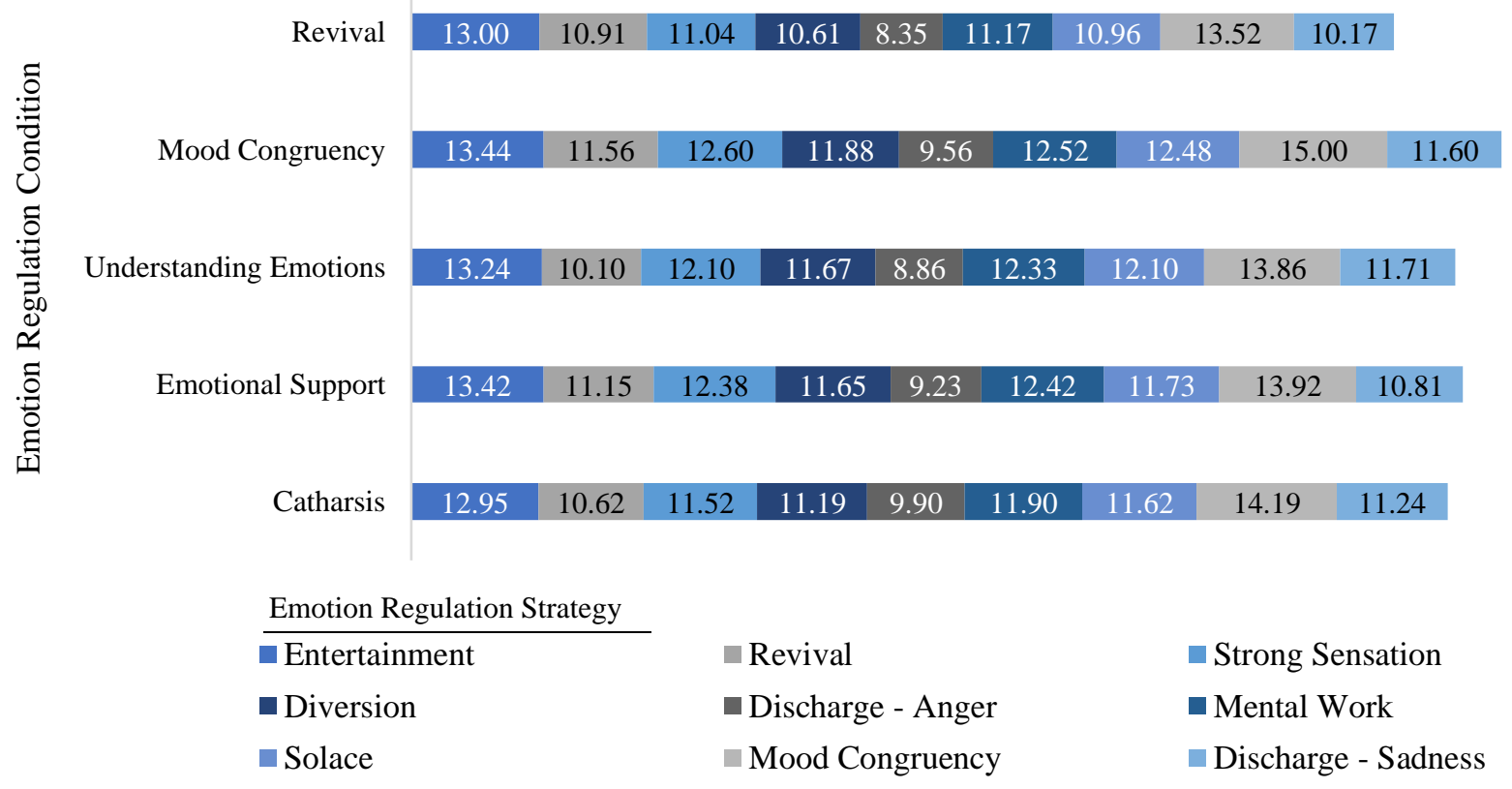

Figure 2. Average preference for typical use of nine emotion regulation strategies for participants in the separate emotion regulation conditions. 


\section{Sadness}

As a manipulation check in order to test whether the sad movie clip successfully induced sadness, a repeated measures ANOVA was conducted incorporating time (i.e., before watching the film clip from Marley \& Me, after watching the clip, and after listening to music) as the within-subjects factor while emotion regulation condition served as the between-subjects factor. The dependent variable was sadness scores from the PANAS-X Sadness subscale. Descriptive statistics are provided in Table 4. Mauchly's test of sphericity was violated, and degrees of freedom were corrected using Huynh-Feldt. This revealed a significant main effect of time, $F(1.95,228.40)=127.44, p<.001$, partial $\eta_{2}=.52$, where sadness significantly increased by an average of 4.56 from before to after the film clip, $p<.001$, and significantly decreased by an average of 3.69 from after the film clip to after music listening, $p<.001$.

The three-by-five (time-by-condition) interaction was not significant, $F(7.81,228.40)=$ $1.83, p=.074$, partial $\eta_{2}=.06$. However, experimental condition would not have impacted sadness scores from before the clip to after the clip, as was confirmed by the repeated contrasts, $F(4,117)=.06, p=.994$, partial $\eta_{2}=.002$. The two-by-five (time-by-condition) interaction effect from after the film clip to after music listening, which is where experimental condition came into play, was significant, $F(4,117)=3.02, p=.021$, partial $\eta_{2}=.09$ (see Figure 3 ). From after the film clip to after music listening, participants in the revival condition experienced the greatest average decrease in sadness by 5.46 points, followed by participants in the emotional support condition (average decrease of 4.00 points), participants in the catharsis condition (average decrease of 3.48), participants in the mood congruency condition (average decrease of 3.16), with participants in the understanding emotions condition experiencing the lowest average decrease in sadness by 2.35 points. These exploratory analyses revealed that, on average, 
participants selected songs that reduced their sadness regardless of the emotion regulation strategy they used. Although participants in the revival condition experienced the greatest decrease in their sadness, Scheffe post hoc tests indicated that this change was only significantly greater than the decrease in sadness experienced by participants in the understanding emotions condition $(p=.035)$. Although these changes in sadness after music listening were only outlined as an exploratory main hypothesis, these results suggest that all of these emotion regulation strategies are comparable in reducing sadness when they involve music listening.

Table 4

Means and Standard Deviations for Participant Sadness Before and After the Film Clip and After Music Listening Across Experimental Conditions

\begin{tabular}{cccc}
\hline Condition & Before Film Clip & After Film Clip & After Music Listening \\
\hline Catharsis & $8.52(4.21)$ & $13.05(3.89)$ & $9.57(3.34)$ \\
Emotional Support & $7.93(3.73)$ & $12.37(4.47)$ & $8.37(4.42)$ \\
Understanding Emotions & $8.48(3.44)$ & $13.04(3.93)$ & $10.70(4.15)$ \\
Mood Congruency & $9.16(4.75)$ & $13.56(5.45)$ & $10.40(4.73)$ \\
Revival & $8.77(4.09)$ & $13.62(5.60)$ & $8.15(4.29)$ \\
Overall & $8.57(4.02)$ & $13.12(4.71)$ & $9.39(4.30)$ \\
\hline
\end{tabular}

14

13

12

11

10

9

8

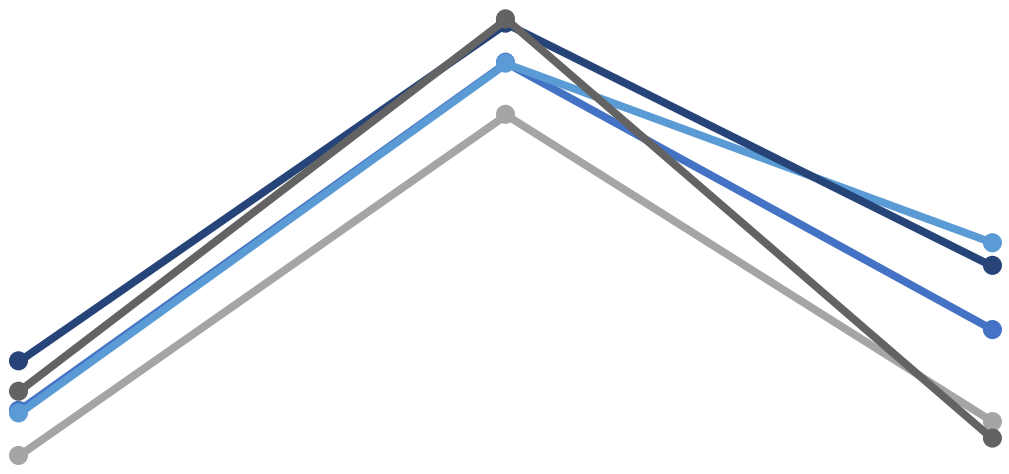

7

Before Clip

After Clip

After Music

- Catharsis - Emotional Support $\longrightarrow$ Understanding Emotions $\longrightarrow$ Mood Congruency $\longrightarrow$ Revival

Figure 3. Change in average sadness from before and after the film clip and after listening to music. The individual lines represent the different emotion regulation conditions. 


\section{Reasons for Listening to Sad Music}

As one of my main hypotheses, I expected participants to rate catharsis, emotional support, understanding emotions, and mood congruency, compared to revival and other nonemotion regulation reasons, as the four that they are most likely to use when choosing to listen to sad music when they are already feeling sad. A repeated-measures ANOVA using participant responses for the Reasons for Listening to Sad Music Questionnaire was used to determine whether there were significant differences between the ratings for the emotion regulation strategies. Sphericity was again violated with this analysis, so the Huynh-Feldt statistic was used. This indicated significant differences in average likelihood between the reasons why individuals choose to listen to sad music when feeling sad, $F(6.89,833.85)=97.62, p<.001$, partial $\eta_{2}=.45$ (see Figure 4).

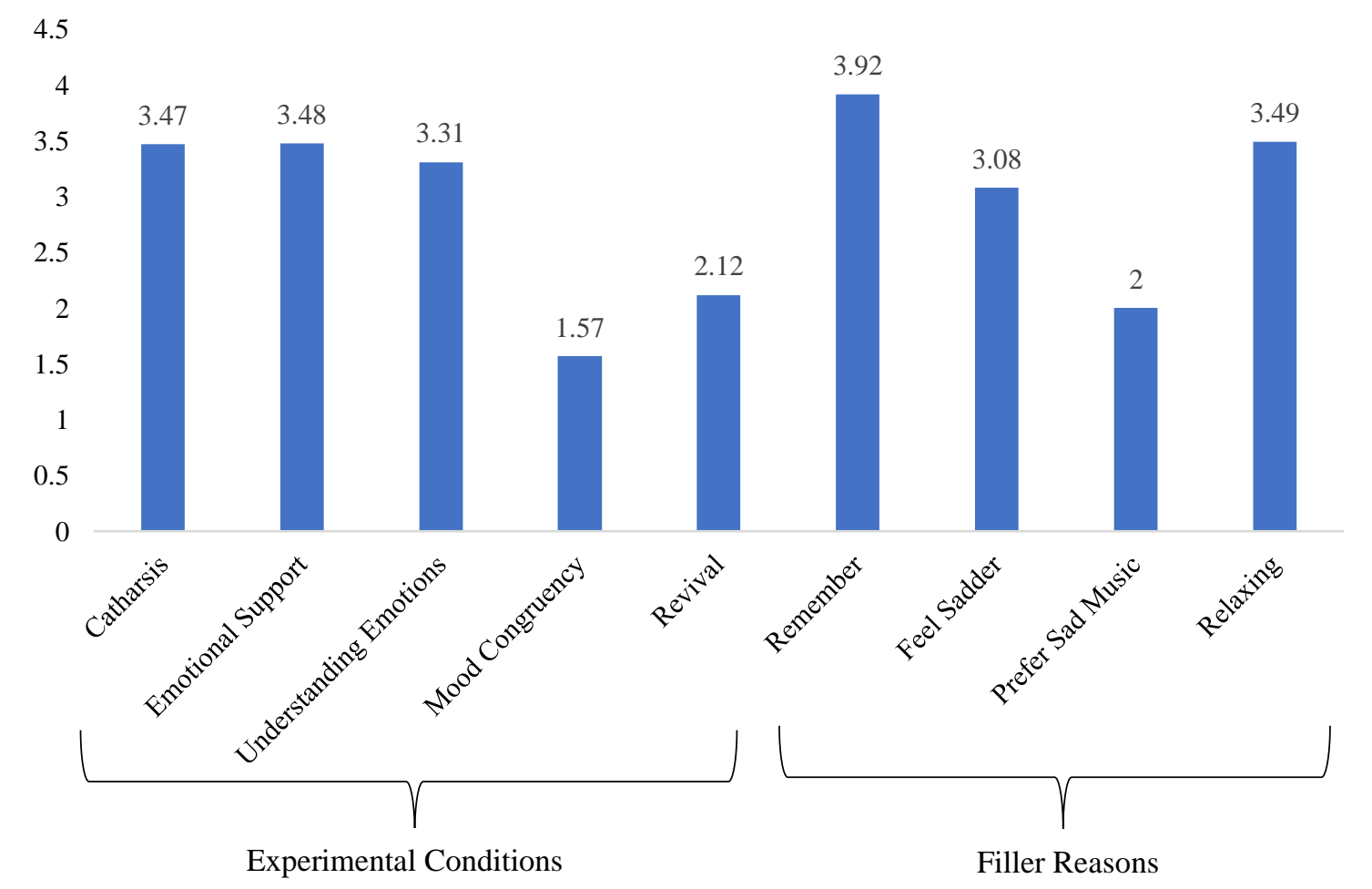

Figure 4. Average likelihood of listening to sad music when feeling sad for each of the nine reasons included on the Reasons for Listening to Sad Music Questionnaire. 
Pairwise comparisons with a Bonferroni adjustment were then examined to identify significant differences in the likelihood of participants using each these reasons. Listening to sad music in order to remember past people or experiences was rated as the most likely reason participants were to listen to sad music when already feeling sad. This average likelihood was significantly higher than the average likelihood of listening to sad music for each of the other eight reasons, all $p \mathrm{~s}<.05$. The average likelihoods of listening to sad music for the reasons of catharsis, because it makes listeners feel sadder, because it helps listeners understand their emotions, because it provides listeners with emotional support, and because listeners find it relaxing when they are already feeling sad were not significantly different from each other. However, these average likelihoods were significantly higher than the average likelihoods for the reasons of always preferring to listen to sad music, mood congruency, and revival, all $p$ s $<.001$. The average likelihoods for always preferring to listen to sad music and revival were not significantly different from one another, but they were both significantly higher than that for mood congruency, $p \mathrm{~s}<.01$. Although some of the experimental emotion regulation strategies had significantly higher ratings than the non-emotion regulation reasons, this was not always the case and only partially supported my hypothesis.

\section{Song Satisfaction}

A one-way, between-subjects ANOVA was conducted to determine differences in average song satisfaction scores for participants in the catharsis $(M=16.38, S D=2.33)$, emotional support $(M=16.70, S D=2.28)$, understanding emotions $(M=16.30, S D=2.42)$, mood congruency $(M=16.20, S D=2.47)$, and revival $(M=16.31, S D=2.59)$ conditions. As another main hypothesis, I had hypothesized that catharsis, emotional support, understanding emotions, and mood congruency participants would experience greater satisfaction with their 
song choices compared to participants in the revival condition. However, results indicated that the differences in song satisfaction were not statistically significant, $F(4,117)=.17, p=.955$, partial $\eta_{2}=.01$

\section{Song Emotionality}

For my final main hypotheses, and to examine differences in song emotionality across the five experimental conditions, beats per minute (BPM), key, and external ratings were used. First, a one-way between-subjects ANOVA was utilized to examine differences in BPM in the songs selected by participants in the different experimental conditions. Seven songs were excluded from this analysis because the BPM obtained from Tunebat and BPMKey did not match. I predicted that the songs selected by participants in the catharsis, emotional support, understanding emotions, and mood congruency conditions would have fewer beats per minute (BPM) than songs selected by participants in the revival condition. Overall, this hypothesis was not supported as the average BPM for songs selected by participants in the catharsis $(M=$ 110.80, $S D=25.80)$, emotional support $(M=120.76, S D=32.07)$, understanding emotions $(M=$ $106.48, S D=23.64)$, mood congruency $(M=115.21, S D=26.94)$, and revival $(M=113.83, S D$ $=26.38)$ conditions were not significantly different, $F(4,110)=.90, p=.467$, partial $\eta_{2}=.03$.

A binary logistic regression was used to determine whether emotion regulation condition led to differences in the likelihood of selecting a song in a major or minor key. Again, songs would have been excluded from this analysis if the key obtained from Tunebat and BPMKey did not match. However, in this case, there was $100 \%$ agreement in the key identified for all songs in Tunebat and BPMKey. In this model, emotion regulation condition served as the predictor variable, where revival was used as the comparison group, and song key was the criterion variable. I expected songs selected by participants in all conditions, except revival, to more often 
be in a minor key. The fit of this binary logistic regression model was not significant and indicated that there was not a relation between emotion regulation condition and key of the songs selected by participants, $\chi_{2}(4)=1.89, p=.757$. In addition, only $2.6 \%$ (Nagelkerke $R 2$ ) of the variance in song key was explained by emotion regulation condition. None of the participants in the other emotion regulation conditions were significantly more or less likely to select a song in a major key compared to participants in the revival condition.

Finally, song emotionality (as rated by external judges) was examined by using the average ratings from external raters of perceived song happiness, sadness, calming, arousing, speed, and familiarity. To complement the other two song emotionality hypotheses, I expected the external raters to rate songs chosen for catharsis, emotional support, understanding emotions, and mood congruency as sadder, less arousing, calmer, and slower than songs selected for revival. I also expected songs selected for revival would be rated as happier, more arousing, less calm, and faster than songs selected for the other strategies. A one-way MANCOVA using emotion regulation condition as the independent variable, familiarity as the covariate, and average happiness, sadness, calming, arousing, and speed ratings as the dependent variables was conducted. Descriptive statistics are provided in Table 5. The MANCOVA revealed a main effect of experimental condition when controlling for song familiarity, Wilks' $\Lambda=.58, F(20$, $372.41)=3.34, p<.001$, partial $\eta_{2}=.13$. Pairwise comparisons were then examined to identify significant differences between conditions.

\section{Happiness}

Songs selected by participants in the revival condition had happiness ratings that were significantly higher than songs selected by participants in the catharsis $(p=.011)$, understanding emotions $(p=.001)$, and mood congruency $(p<.001)$ conditions, but not the emotional support 
condition, $p=1.00$. Songs selected by participants in the emotional support condition had significantly higher happiness ratings than songs selected by participants in the understanding emotions $(p=.012)$ and mood congruency $(p=.003)$ conditions, but not the catharsis condition, $p=.090$.

\section{Sadness}

Songs selected by participants in the revival condition had sadness ratings that were significantly lower than songs selected by participants in the catharsis $(p<.001)$, emotional support $(p=.015)$, understanding emotions $(p<.001)$, and mood congruency $(p<.001)$ conditions. This confirms the portion of the hypothesis stating that songs selected by participants in these four emotion regulation conditions will be rated as sadder than those songs selected by participants in the revival condition. In addition, songs selected by participants in the emotional support condition had sadness ratings that were significantly lower than songs selected by participants in the mood congruency condition, $p=.042$.

\section{Calming}

Songs selected by participants in the revival condition had calming ratings that were significantly lower than songs selected by participants in the catharsis $(p=.002)$, emotional support $(p=.012)$, understanding emotions $(p=.009)$, and mood congruency $(p=.026)$ conditions. There were no significant differences in calming ratings for songs selected by participants in the catharsis, emotional support, understanding emotions, and mood congruency conditions.

\section{Arousing}

Songs selected by participants in the revival condition had arousing ratings that were significantly higher than songs selected by participants in the catharsis $(p=.024)$ and 
understanding emotions $(p=.009)$ conditions, but not the emotional support $(p=.186)$ and $\operatorname{mood}$ congruency $(p=.073)$ conditions. This only partially supported the hypothesis as songs selected for revival were only rated as more arousing that the songs selected for catharsis and understanding emotions. There were no significant differences in arousing ratings for songs selected by participants in the catharsis, emotional support, understanding emotions, and mood congruency conditions.

\section{Speed}

Finally, songs selected by participants in the revival condition had speed ratings that were significantly higher than songs selected by participants in the catharsis $(p=.001)$, emotional support $(p=.005)$, understanding emotions $(p<.001)$, and mood congruency $(p<.001)$ conditions. There were no significant differences in speed ratings for songs selected by participants in the catharsis, emotional support, understanding emotions, and mood congruency conditions. Once again, this supports the final component of the song emotionality hypothesis. Average speed ratings also had a very small, positive correlation with BPM obtained from Tunebat, but this correlation was not significant, $r=.13, p=.152$. This indicates that although BPM and perceived speed are positively related, differences between the two may still exist. 
Table 5

Means and Standard Deviations for Emotionality Ratings Completed by External Ratings for Songs Selected by Participants in Each of the Emotion Regulation Conditions

\begin{tabular}{cccccc}
\hline & \multicolumn{5}{c}{ Emotion Regulation Condition } \\
\cline { 2 - 6 } & Catharsis & $\begin{array}{c}\text { Emotional } \\
\text { Support }\end{array}$ & $\begin{array}{c}\text { Understanding } \\
\text { Emotions }\end{array}$ & $\begin{array}{c}\text { Mood } \\
\text { Congruency }\end{array}$ & Revival \\
\hline Happiness & $2.17(0.76)$ & $2.81(1.27)$ & $2.02(0.96)$ & $1.74(0.71)$ & $3.06(0.95)$ \\
Sadness & $2.76(0.97)$ & $2.11(1.15)$ & $2.80(1.08)$ & $2.84(0.98)$ & $1.29(0.40)$ \\
Calming & $2.62(0.89)$ & $2.44(0.81)$ & $2.50(0.81)$ & $2.40(0.83)$ & $1.67(0.87)$ \\
Arousing & $1.95(0.72)$ & $2.07(0.95)$ & $1.91(0.90)$ & $1.86(0.71)$ & $2.63(0.84)$ \\
Speed & $2.48(0.91)$ & $2.63(0.67)$ & $2.43(0.64)$ & $2.40(0.78)$ & $3.37(0.66)$ \\
\hline
\end{tabular}




\section{CHAPTER V: DISCUSSION}

Emotion regulation has been examined in a variety of frameworks, including as it relates to listening to music. Specifically, Saarikallio (2008) identified entertainment, revival, strong sensation, diversion, discharge, mental work, and solace as the seven emotion regulation strategies that are implemented when an individual chooses to listen to music. Although some of these strategies seem target a specific emotion, such as solace (sadness) and discharge (anger), and music with some emotionality, such as diversion (pleasant music), as a whole they are fairly broad and cover a wide range of emotions. Generally, the goal of emotion regulation is to reduce negative emotions and increase positive ones (e.g., Gross, 1998b; Millgram et al., 2015; Tamir, 2016; van Goethem \& Sloboda, 2011), and any combination of emotion and music emotionality can be used to achieve this. One example of this is listening to sad music when in a sad emotional state, which is a form of the "tragedy paradox" (Sachs et al., 2015). The reason this practice may occur could be due to our use of the emotion regulation strategies of catharsis, emotional support, understanding emotions, and mood congruency (Friedman et al., 2012;

Garrido \& Schubert, 2013; Sedikides, 1992; Taylor \& Friedman, 2015; van Goethem \& Sloboda, 2011). This study sought to confirm that these four emotion regulation strategies are those that are used when an individual chooses to listen to sad music when in a sad emotional state.

\section{Typical Emotion Regulation Preferences}

I had hypothesized that prior to the start of the experiment all participants would have similar preferences for how they typically use music for emotion regulation. This was examined as a way to ensure that the success of the experimental manipulation was not affected by preexisting emotion regulation preferences. This hypothesis was supported and indicates that it is unlikely that any other findings were impacted by typical preferences for emotion regulation 
using music using the strategies outlined by Saarikallio (2008, 2012). However, additional analyses would be needed to ensure the accuracy of this assumption, as these preferences were not explicitly controlled for in any other analyses.

\section{Emotion Regulation Strategies When Choosing Music}

Multiple researchers have suggested that catharsis, emotional support, understanding emotions, and mood congruency are the emotion regulation strategies individuals may implement when listening to sad music when feelings sad (Garrido \& Schubert, 2011, 2013; Levinson, 1990; Norton, 2011; Sedikides, 1992; Stapley, 2014; van Goethem \& Sloboda, 2011). Thus, I expected participants to rate these four strategies as the most likely reasons they would choose to listen to sad music when feeling sad compared to other filler reasons. This hypothesis was not entirely supported. Selecting a song to remember past people or experiences was the most likely reason participants would choose to listen to sad music when feeling sad compared to all of the other options. Participants did indicate that they are more likely to listen to sad music for catharsis, understanding emotions, and emotional support compared to mood congruency, revival, and always preferring to listen to sad music. Mood congruency happened to be the least likely reason participants would choose to listen to sad music when feeling sad. As discussed below, selecting a song to remember past people or experiences may not be considered an emotion regulation strategy by itself, and selecting a song for mood congruency may occur in conjunction with another emotion regulation strategy.

As hypothesized, the manipulation checks suggest that the experimental manipulation, the different emotion regulation conditions, was successful in the sense that most participants were able to identify the instructions they were given to use when selecting a song of their choice to listen to before and after music listening. However, when asked to rate the extent to which 
each set of instructions (with each set corresponding to each of the five strategies) played into their song selection decision, only participants in the revival condition rated the revival instructions as playing into their decision to a greater extent than the participants in all other conditions. In addition, the participants in the other conditions only consistently rated their respective instructions as playing into their song choice to a greater extent compared to participants in the revival condition. This suggests that these four emotion regulation strategies are different from revival but are not necessarily mutually exclusive from each other and may occur concurrently. In fact, the qualitative responses provided by participants about why they chose the songs that they did suggest this explanation may be true.

When discussing which categories were prevalent across the participant responses, researchers discussed the possibility of some explanations falling under multiple categories. Participant responses such as "I like the beat of the song and the meaning as well. I personally think it is kind of a sad song, which helped me express my depressed feelings after watching a dog die" and "I chose the song You Make My Dreams Come True by Hall and Oates because it's super upbeat and positive. It has a really catchy beat and it always cheers me up because I think of the scene from 500 Days of Summer where he is dancing through the park listening to the song" are examples of when this approach may have been appropriate. For consistency and simplicity, responses were not included under multiple categories, and were only included under one. Previous research does suggest that spontaneous emotion regulation, at least in response to a disgust inducing film clip, led participants to utilize multiple emotion regulation strategies (Aldao \& Nolen-Hoeksema, 2013). Saarikallio et al. (2012) has also found that when individuals choose to listen to music that matches their mood, they are more likely to use the emotion regulation strategies of discharge (i.e., catharsis) and solace (i.e., emotional support). Therefore, 
it may be the case that a similar phenomenon was happening here, where participants were naturally using multiple strategies, even if they were only given the instructions for one.

\section{Emotion Regulation Strategy Success}

In order to measure the success of catharsis, emotional support, understanding emotions, and mood congruency as emotion regulation strategies that use sad music when experiencing sadness, I expected participants to be more satisfied with their song choices in these four conditions compared to participants in the revival condition. Results did not indicate that this was the case, as participants in all conditions did not indicate significantly different satisfaction with their song choices. This may have happened, in part, because participants were able to select any song they wanted. Because participants were not forced to select a specific song, and only given instructions for how to pick one, they may have expressed the same levels of satisfaction regardless of the song they may have chosen. Lower song satisfaction scores could have been driven more by the realization that they could have picked a different song they would have preferred listening to more, not that their song selection instructions (or assigned emotion regulation strategy) led them to select a song that they ordinarily would not have picked when experiencing sadness. In addition, this measure of satisfaction may not have been an appropriate way to determine the success of these strategies. Instead, it may be changes in feelings of sadness that better indicate whether these emotion regulation strategies are successful.

Previous studies have suggested that using a sad film clip would successfully induce sadness in participants (e.g., Kahn et al., 2017, 2019). These findings were supported in this study as well, by using the clip from the ending to the movie Marley \& Me. Participants indicated that they were experiencing greater feelings of sadness after the film clip compared to beforehand. My exploratory analysis to determine changes of sadness after music listening 
indicated that, regardless of the emotion regulation strategy used, all participants experienced significant decreases in their feelings of sadness. Randall et al. (2014) found something similar, where music listening while experiencing an emotion with a negative valence led to a positive shift in the emotional valence that was being experienced. Zavoyskiy et al. (2016) also found that participants who were experiencing sadness saw general improvements in their mood after listening to happy or sad music. Since my analyses only examined average sadness scores, it's not known whether any participants chose to listen to music as a way to enhance their negative emotions (Garrido \& Schubert, 2013; Randall \& Rickard, 2017; Sakka \& Juslin, 2018; van Goethem \& Sloboda, 2011). In addition, the results indicated that the only significant difference in changes in sadness was between participants using revival and participants using understanding emotions. Participants using revival experienced a significantly greater decrease in their sadness compared to the decrease in sadness experienced by participants using understanding emotions. This further suggests that most of the emotion regulation strategies are equally successful in reducing feelings of sadness, even without taking into account the type of music they chose to listen to.

\section{Song Emotionality}

Finally, I hypothesized the songs that participants selected in the catharsis, emotional support, understanding emotions, and mood congruency conditions to be more often in a minor key and have a lower BPM compared to songs selected by participants in the revival condition. This was based on other research that states that negatively valenced music typically has a slower tempo and is in a minor key (Ramos et al., 2011; Webster \& Weir, 2005). Other research has also found that as BPM increases, ratings of happiness increase and sadness ratings decrease (Fernández-Sotos et al., 2016). The results of this study did not indicate that this was true, as 
tempo was not significantly different for songs selected in any of the conditions, nor did emotion regulation condition predict whether songs would be in a major or minor key.

However, as another measure of song emotionality, I believed external raters would rate those songs from the catharsis, emotional support, understanding emotions, and mood congruency as being sadder, less arousing, calmer, and slower compared to songs from the revival condition. Songs selected by participants in these four conditions were rated as significantly sadder, calmer, and slower than songs selected for revival. External ratings indicated that only songs selected by participants in the catharsis and understanding emotions conditions were rated as significantly less arousing than songs selected for revival. Using revival also led participants to select songs that were rated as significantly happier that songs selected using catharsis, understanding emotions, and mood congruency, but not emotional support.

Collectively, these findings suggest that how individuals interpret the emotionality of music may differ from how it is determined "objectively" by using key and BPM. This supports van Goethem and Sloboda's (2011) findings that musical features, such as type, familiarity, and content, are the most common reasons an individual selects specific music to listen to for the purposes of emotion regulation. In this case, controlling for how familiar the songs were to the external raters still resulted in the music selected by participants in all conditions, except for revival, as being rated as sad, slow, and calm. It may be these other features in music (e.g., familiarity, lyrics/content, and type), beyond the music theory and structure, that are more accurate measures or determinants of emotionality. Additionally, despite the fact that all participants indicated experiencing greater sadness after the film clip, these differences in song emotionality can add to some findings of other researchers who found that, in general, individuals who are experiencing sadness will listen to sad and slow music more often compared 
to individuals who are not feeling sad (Chen et al., 2007; Friendman et al., 2012; Hunter et al., 2011; Lee et al., 2013; Randall \& Rickard, 2017; Taruffi \& Koelsch, 2014; except O’Malley et al., 2016). The results of this study suggest that it is the underlying emotion regulation strategy (revival versus others) we are implementing when we are feeling sad that determines the emotionality of our music choice. Participants in the revival condition experienced an increase in sadness after the film clip (like participants in all other conditions), but they still chose music that was significantly happier despite their sad feelings. So even though all participants, except those using revival, chose sad music to listen to after experiencing an increase in their sad feelings, doing so for catharsis, emotional support, understanding emotions, and mood congruency led to significant decreases in these feelings of sadness.

\section{Limitations}

There were a few limitations that were associated with this study. First, based on the power analysis, any small to medium effects may not have been detected. This could be one explanation for why some of the results may not have been statistically significant. For example, it is possible that significant differences could not be detected between groups for song satisfaction scores because observed power was only .08; and observed power when examining differences in song BPM across groups was only .28. In addition, the manipulation checks were only able to confirm that the participants could identify the instructions they were given when selecting a song to listen to. Even though participants were able to respond to these checks correctly, it does not necessarily mean that participants understood how to pick a song based on those instructions, nor could it confirm that they actually picked a song using these instructions. Participants were also only able to use the Spotify account that was provided during the experimental session, they were unable to use their own Spotify account or another search 
engine. Therefore, participants may have only selected one of the first songs that they could think of, and that song may not have been the most appropriate or satisfying even if they did follow their instructions correctly.

Attempting to manipulate emotion regulation may have also been impacted by the lab setting used in this study. There were some participants who verbally expressed that they were trying to control their emotions after watching the Marley \& Me clip, typically in reference to refraining from crying. This suggests that participants may have begun using suppression to regulate their emotions from the time they started watching the film clip. If this were the case, it may have masked the effects of, or minimized their ability to effectively use, the emotion regulation strategy they were given for the purposes of song selection. Although results indicated that, generally speaking, participants were not more likely to use any of the emotion regulation strategies using music (as indicated by B-MMR subscale scores), participants may prefer one emotion regulation strategy over another in specific sadness-inducing situations. In, previous research, individuals indicated they were more likely to use solace (i.e., emotional support) in certain situations, such as after the loss of a loved one or pet, when experiencing problems in a relationship, when experiencing general stress, etc. (Hanser, ter Bogt, van den Tol, Mark, \& Vingerhoets, 2016). In this study, the film clip may have naturally led some individuals to select sad music for catharsis over the others, while others may have preferred listening to sad music that provided them with emotional support after watching a sad film clip. Not allowing participants to freely select which emotion regulation strategy to use may have also impacted the results.

Some caution should also be used when interpreting some of these findings due to the absence of a control group. It is possible that the changes in sadness that were visible across all 
conditions may not have been due to emotion regulation strategy, listening to music, or music choice. Instead, decreases in sadness may have resulted naturally from the passage of time after the film clip. As mentioned above, the use of an entirely different emotion regulation strategy, such as suppression, during and immediately after the film clip could have also led to these decreases in sad feelings.

This study also utilized multiple novel measures. The Reasons for Listening to Sad Music Questionnaire, Song Satisfaction Scale, Song Selection Survey, and Song Rating Scale were all created for this study. These measures were not formally developed through pilot studies or other formal data collection. Therefore, none of these measures may have scores with acceptable reliability or validity. The mood congruency and discharge - sadness subscales were also created and added to the Brief Music in Mood Regulation Scale. Again, these subscales were not validated, and reliability was not established prior to their use. A formal factor analysis was also not completed, meaning the individual items may not officially load onto the two subscale constructs.

Finally, the three external raters who rated the emotionality of the songs selected by participants had relatively low reliability. Interrater reliability is typically considered to be acceptable when it is .80 or higher (Heiman, 2001). This lower reliability may have been due to the external raters not following the proper instructions when completing their ratings (e.g., listening to the songs in blocks of time longer than $30 \mathrm{~min}$ ). It may have also been driven by musical preferences or familiarity with certain genres of music. Although significant differences were found in the songs selected by participants in different conditions while controlling for familiarity, this familiarity may have still inflated these reliability issues. 


\section{Future Directions}

Additional research may be needed in order to solidify catharsis, emotional support, understanding emotions, and mood congruency as successful emotion regulation strategies used in sad emotional states when choosing to listen to sad music. One way to do this would be to allow participants to independently select how they would like to regulate their emotions, and then pick a song to listen to based on that choice. This could help determine if these four emotion regulation strategies are used when listening to sad music when feeling sad. The Song Selection Questionnaire also suggests that these strategies may not be mutually exclusive, as some of the emotion regulation instructions played into participants' song decision similarly. Allowing participants to choose how to regulate their emotions may help clarify whether any of these strategies commonly coincide with one another.

The Reasons for Listening to Sad Music Questionnaire indicated that individuals are significantly more likely to listen to sad music in order to remember individuals or past experiences compared to all other reasons that were included on that measure. Based on the qualitative analysis, brings back a memory also had the greatest number of responses across all participants compared to all other response categories. These results indicate that remembering people, experiences, or memories is important for individuals when they listen to sad music when experiencing sadness. It may be beneficial to explore this further to determine if this could also happen in conjunction with another emotion regulation strategy (as discussed above) or if this is an independent emotion regulation strategy. For example, individuals may listen to sad music as a way to remember a past experience, but that music is also providing them with emotional support as they think about that experience (Hanser et al., 2016). It may also be the case that listening to sad music is very dependent on the sadness-inducing situation. As Thoma, 
Ryf, Mohiyeddini, Ehlert, and Nater (2012) found, song choice preference differed across different emotional situations. If individuals are most often feeling sad because of loved ones that they have lost or past experiences that have led to their sad feelings, it makes sense that individuals would then listen to sad music because they are thinking about these memories, inflating this result. Therefore, these emotion regulation strategies should be compared across different sadness-inducing situations. We may find that the success of each strategy, as well as the likelihood that each is used, depends on how or why individuals are feelings sad.

\section{Conclusions}

This study aimed at confirming that catharsis, emotional support, understanding emotions, and mood congruency are the four emotion regulation strategies people implement when they choose to listen to sad music when experiencing sadness. It was the first to integrate these four strategies into a single experimental study from a variety of other sources in the literature (Friedman et al., 2012; Garrido \& Schubert, 2013; Sedikides, 1992; Taylor \& Friedman, 2015; van Goethem \& Sloboda, 2011). Results indicate that, regardless of emotion regulation strategy used, participants generally experienced improvements in their sad feelings after listening to their song of choice. However, the songs selected by participants using catharsis, emotional support, understanding emotions, and mood congruency were significantly sadder, slower, and calmer than songs selected by participants using revival (an emotion regulation strategy believed to use happy music). This suggests that, although these four strategies may not be different from each other, they are different from revival, and possibly other strategies, in the emotionality of the songs that are utilized with them. Although participants did not identify these four strategies as being the top four reasons they decide to listen to sad music when feelings sad, these findings may have resulted from these strategies not 
being mutually exclusive from one another. Future research would benefit from pursuing this topic further and determining whether there are situational differences in when these different emotion regulation strategies are used and if any or all of them can be used simultaneously. 


\section{REFERENCES}

Aldao, A. \& Nolen-Hoeksema, S. (2013). One versus many: Capturing the use of multiple emotion regulation strategies in response to an emotion-eliciting stimulus. Cognition and Emotion, 27, 753-760. http://dx.doi.org/10.1080/02699931.2012.739998

Barrett, L. F., Mesquita, B., Ochsner, K. N., \& Gross, J. J. (2007). The experience of emotion. Annual Review of Psychology, 58, 373-403. https://doi.org/10.1146/annurev.psych.58.110405.085709

Barrett, L. F., Ochsner, K. N., \& Gross, J. J. (2007). On the automaticity of emotion. In J. A. Bargh (Ed.), Social psychology and the unconscious: The automaticity of higher mental processes (pp. 173-217). New York: Psychology Press.

Barrett, L. F., Quigley, K. S., Bliss-Moreau, E., \& Aronson, K. R. (2004). Interoceptive sensitivity and self-reports of emotional experience. Journal of Personality and Social Psychology, 87, 684-697. http://dx.doi.org/10.1037/0022-3514.87.5.684

Bodner, E. \& Bensimon, M. (2014). Problem music and its different shades over its fans. Psychology of Music, 43, 641-660. http://doi.org/10.1177/0305735614532000

Braunstein, L. M., Gross, J. J., \& Ochsner, K. N. (2017). Explicit and implicit emotion regulation: A multi-level framework. Social Cognitive and Affective Neuroscience 12, 1545-1557. http://doi.org/10.1093/scan/nsx096

Cannon, W. B. (1927). The James-Lange theory of emotions: A critical examination and an alternative theory. The American Journal of Psychology, 39, 106-124. http://doi.org/10.2307/1415404 
Chen, L., Zhou, S., \& Bryant, J. (2007). Temporal changes in mood repair through music consumption: Effects of mood, mood salience, and individual differences. Media Psychology, 9, 695-713. http://doi.org/10.1080/15213260701283293

Chin, T. \& Rickard, N. S. (2014). Emotion regulation strategy mediates both positive and negative relationships between music uses and well-being. Psychology of Music, 42, 692713. http://doi.org/10.1177/0305735613489916

Corrigall, K. A. \& Schellenberg, G. (2013). Music: The language of emotion. In C. Mohiyeddini, M. Eysenck, \& S. Bauer (Eds.), Handbook of psychology of emotions: Recent theoretical perspectives and novel empirical findings (Vol. 2, pp. 299-325). New York: Nova Science Publishers, Inc.

Dewey, J. (1894). The theory of emotion: Emotional attitudes. Psychological Review, 1, 553569. http://dx.doi.org/10.1037/h0069054

Dewey, J. (1895). The theory of emotion: The significance of emotions. Psychological Review, 2, 13-32. http://dx.doi.org/10.1037/h0070927

Dingle, G. A. \& Fay, C. (2017). Tuned In: The effectiveness for young adults of a group emotion regulation program using music listening. Psychology of Music, 45, 513-529. http://doi.org/10.1177/0305735616668586

Dror, O. E. (2017). Deconstruction the "two factors": The historical origins of the SchachterSinger theory of emotions. Emotion Review, 9, 7-16. http://doi.org/10.1177/1754073916639663

Ekman, P. \& Friesen, W. V. (1969). The repertoire of nonverbal behavior: Categories, origins, usage, and coding. Semiotica, 1, 49-68. http://doi.org/10.1515/semi.1969.1.1.49 
English, T., Lee, I. A., John, O. P., \& Gross, J. J. (2017). Emotion regulation strategy selection in daily life: The role of social context and goals. Motivation and Emotion, 41, 230-242. http://doi.org/10.1007/s11031-016-9597-z

Fernández-Sotos, A., Fernández-Caballero, A., \& Latorre, J. M. (2016). Influence of tempo and rhythmic unit in musical emotion regulation. Frontiers in Computational Neuroscience, 10, article 80. http://doi.org/10.3389/fncom.2016.00080

Field, A. (2013). Discovering statistics using IBM SPSS statistics (4th ed.). Thousand Oaks, CA: SAGE Publications.

Ford, B. Q. \& Gross, J. J. (2018). Emotion regulation: Why beliefs matter. Canadian Psychology/Psychologie canadienne, 59, 1-14. http://doi.org/10.1037/cap0000142

Friedman, R.S., Gordis, E., \& Förster, J. (2012). Re-exploring the influence of sad mood on music preference. Media Psychology, 15, 249-266. http://doi.org/10.1080/15213269.2012.693812

Garrido, S. \& Schubert, E. (2011). Negative Emotion in Music: What is the Attraction? A qualitative study. Empirical Musicology Review, 6, 214-230. http://doi.org/10.18061/1811/52950

Garrido, S. \& Schubert, E. (2013). Adaptive and maladaptive attraction to negative emotions in music. Musicae Scientiae, 17, 147-166. http://doi.org/10.1177/1029864913478305

Gellhorn, E. (1961). Prolegomena to a theory of the emotions. Perspectives in Biology and Medicine, 4, 403-436. http://doi.org/10.1353/pbm.1961.0014

Ghafur, R. D., Suri, G., \& Gross, J. J. (2018). Emotion regulation choice: The role of orienting attention and action readiness. Current Opinion in Behavioral Sciences, 19, 31-35. http://dx.doi.org/10.1016/j.cobeha.2017.08.016 
Greenwood, D. N. \& Long, C. R. (2009). Mood specific media use and emotion regulation:

Patterns and individual differences. Personality and Individual Differences, 46, 616-621. http://doi.org/10.1016/j.paid.2009.01.002

Gross, J. J. (1998a). Antecedent- and response-focused emotion regulation: Divergent consequences for experience, expression, and physiology. Journal of Personality and Social Psychology, 74, 224-237. http://dx.doi.org/10.1037/0022-3514.74.1.224

Gross, J. J. (1998b). The emerging field of emotion regulation: An integrative review. Review of General Psychology, 2, 271-299. http://dx.doi.org/10.1037/1089-2680.2.3.271

Gross, J. J. (1999). Emotion regulation: Past, present, future. Cognition and Emotion, 13, 551573. http://doi.org/10.1080/026999399379186

Gross, J. J. (2001). Emotion regulation in adulthood: Timing is everything. Current Directions in Psychological Science, 10, 214-219. http://doi.org/10.1111/1467-8721.00152

Gross, J. J. (2002). Emotion regulation: Affective, cognitive, and social consequences. Psychophysiology, 39, 281-291. http://doi.org/10.1017/S0048577201393198

Gross, J. J. (2015). Emotion regulation: Current status and future prospects. Psychological Inquiry, 26, 1-26. http://doi.org/10.1080/1047840X.2014.940781

Gross, J. J. \& John, O.P. (2003). Individual differences in two emotion regulation processes: Implications for affect, relationships, and well-being. Journal of Personality and Social Psychology, 85, 348-362. http://doi.org/10.1037/0022-3514.85.2.348

Gross, J. J. \& Levenson, R. W. (1993). Emotion suppression: Physiology, self-report, and expressive behavior. Journal of Personality and Social Psychology, 64, 970-986. http://doi.org/10.1037/0022-3514.64.6.970 
Gross, J. J. \& Levenson, R. W. (1997). Hiding feelings: The acute effects of inhibiting negative and positive emotion. Journal of Abnormal Psychology, 106, 95-103. http://doi.org/10.1037//0021-843X.106.1.95

Gross, J. J. \& Thompson, R. A. (2007). Emotion regulation: Conceptual foundations. In J. J. Gross (Ed.), Handbook of emotion regulation (pp. 3-24). New York: Guilford Press.

Hanser, W. E., ter Bogt, T. F. M., van den Tol, A. J. M., Mark, R. E., \& Vingerhoets, A. J. J. M. (2016). Consolation through music: A survey study. Musicae Scientiae, 20, 122-137. http://doi.org/10.1177/1029864915620264

Hatten, R. S. (2010). Aesthetically warranted emotion and composed expressive trajectories in music. Music Analysis, 29, 83-101. http://doi.org/10.1111/j.1468-2249.2011.00327.x

Heiman, G. W. (2001). Understanding research methods and statistics: An integrated introduction for psychology (2nd ed.). Boston, MA: Houghton Mifflin Company.

Hunter, P. G., Schellenberg, E. G., \& Griffith, A. T. (2011). Misery loves company: Moodcongruent emotional responding to music. Emotion, 11, 1068-1072. http://doi.org/10.1037/a0023749

Irons, D. (1894). Prof. James' theory of emotion. Mind, 3, 77-97. http://dx.doi.org/10.1093/mind/III.9.77

John, O. P. \& Gross, J. J. (2004). Healthy and unhealthy emotion regulation: Personality processes, individual differences, and life span development. Journal of Personality, 72, 1301-1334. http://doi.org/10.1111/j.1467-6494.2004.00298.x

Juslin, P. N. (2013). What does music express? Basic emotions and beyond. Frontiers in Psychology, 4. http://doi.org/10.3389/fpsyg.2013.00596 
Juslin, P. N. \& Laukka, P. (2004). Expression, perception, and induction of musical emotions: A review and a questionnaire study of everyday listening. Journal of New Music Research, 33, 217-238. https://doi.org/10.1080/0929821042000317813

Juslin, P. N. \& Lindström, E. (2010). Music expression of emotions: Modelling listeners' judgements of composed and performed features. Music Analysis, 29, 334-364. http://doi.org/10.1111/j.1468-2249.2011.00323.x

Kahn, J. H., Cox, D. W., Bakker, A. M., O’Loughlin, J. I., \& Kotlarczyk, A. M. (2017). The role of distress disclosure tendencies in the experience and expression of laboratory-induced sadness. Journal of Individual Differences, 38, 55-62. http://doi.org/10.1027/1614$0001 / \mathrm{a} 000222$

Kahn, J. H., Cox, D. W., Simons, K. J., Hamlet, A. N., Hodge, B. J., \& Lawell, K. J. (2019). Nonlinear effect of depression symptoms on the time course of emotional reactivity. Motivation and Emotion. http://doi.org/10.1007/s11031-019-09754-0

Lee, C. J., Andrade, E. B., \& Palmer, S. E. (2013). Interpersonal relationships and preferences for mood-congruency in aesthetic experiences. Journal of Consumer Research, 40, 382391. http://doi.org/10.1086/670609

Levinson, J. (1990). Music, art, and metaphysics. Ithaca, NY: Cornell University Press.

Lundin, R. W. (1967). An objective psychology of music (2nd ed.). New York: The Ronald Press Company.

McRae, K., Rhee, S. H., Gatt, J. M., Godinez, D., Williams, L. M., Gross, J. J. (2017). Genetic and environmental influences on emotion regulation: A twin study of cognitive reappraisal and expressive suppression. Emotion, 17, 772-777.

http://doi.org/10.1037/emo0000300 
Millgram, Y., Joormann, J., Huppert, J. D., \& Tamir, M. (2015). Sad as a matter of choice? Emotion-regulation goals in depression. Psychological Science, 26, 1216-1228. http://doi.org/10.1177/0956797615583295

Milyavsky, M., Webber, D., Fernandez, J. R., Kruglanski, A. W., Goldenberg, A., Suri, G., \& Gross, J. (2018). To reappraise or not to reappraise? Emotion regulation choice and cognitive energetics. Emotion. http://dx.doi.org/10.1037/emo0000498

Mursell, J. L. (1932). Psychology of music. Psychological Bulletin, 29, 218-241. http://doi.org/10.1037/h0074849

Mursell, J. L. (1971). The psychology of music. Westport, CT: Greenwood Press, Publishers.

Norton, K. (2011). How music-inspired weeping can help terminally ill patients. Journal of Medical Humanities, 32, 231-243. http://doi.org/10.1007/s10912-011-9140-x

O’Malley, E., Seror III, G. A., \& Friedman, R. S. (2016). Reinvestigating affect-congruency in music choice: Does misery really love company? Psychomusicology: Music, Mind, and Brain, 26, 67-78. http://dx.doi.org/10.1037/pmu0000114

Pribram, K. H. \& Melges, F. T. (1969). Psychophysiological basis of emotion. In P. J. Vinken \& G. W. Bruyn (Eds.), Handbook of clinical neurology (vol. 3, pp. 316-342). Amsterdam: North-Holland Publishing Company.

Ramos, D., Bueno, J. L. O., \& Bigand, E. (2011). Manipulating Greek musical modes and tempo affects perceived musical emotion in musicians and nonmusicians. Brazilian Journal of Medical and Biological Research, 44, 165-172. http://doi.org/10.1590/S0100879X2010007500148 
Randall, W. M. \& Rickard, N. S. (2017). Personal music listening: A model of emotional outcomes developed through mobile experience sampling. Music Perception, 34, 501514. http://doi.org/10.1525/MP.2017.34.5.501

Randall, W. M., Rickard, N. S., \& Vella-Brodrick, D. A. (2014). Emotional outcomes of regulation strategies used during personal music listening: A mobile experience sampling study. Musicae Scientiae, 18, 275-291. http://doi.org/10.1177/1029864914536430

Robertson, E. (1934). The emotional element in listening to music. The Australasian Journal of Psychology and Philosophy, 12, 199-212. http://doi.org/10.1080/00048403408541043

Saarikallio, S. H. (2008). Music in mood regulation: Initial scale development. Musicae Scientiae, 12, 291-309. https://doi.org/10.1177/102986490801200206

Saarikallio, S. H. (2012). Development and validation of the brief music in mood regulation scale (B-MMR). Music Perception: An Interdisciplinary Journal, 30, 97-105. http://doi.org/10.1525/MP.2012.30.1.97

Saarikallio, S., Nieminen, S., \& Brattico, E. (2012). Affective reactions to musical stimuli reflect emotional use of music in everyday life. Musicae Scientiae, 17, 27-39. http://doi.org/10.1177/1029864912462381

Sachs, M. E., Damasio, A., \& Habibi, A. (2015). The pleasures of sad music: A systematic review. Frontiers in Human Neuroscience, 9. http://doi.org/10.3389/fnhum.2015.00404

Sakka, L. S. \& Juslin, P. N. (2018). Emotion regulation with music in depressed and nondepressed individuals: Goals, strategies, and mechanisms. Music \& Science, 1, 1-12. http://doi.org/10.1177/2059204318755023

Schachter, S. \& Singer, J. E. (1962). Cognitive, social, and physiological determinants of emotional state. Psychological Review, 69, 379-399. http://doi.org/10.1037/h0046234 
Schäfer, T., Sedlmeier, P., Städtler, C., \& Huron, D. (2013). The psychological functions of music listening. Frontiers in Psychology, 4. http://doi.org/10.3389/fpsyg.2013.00511

Sedikides, C. (1992). Changes in the valence of the self as a function of mood. In M. S. Clark (Ed.), Emotion and social behavior (The review of personality and social psychology) (vol. 14, pp. 271-311). Thousand Oaks, CA: Sage Publications, Inc.

Shavelson, R. J. (1996). Statistical reasoning for the behavioral sciences (3rd ed.). Needham Heights, MA: Allyn \& Bacon.

Shifriss, R., Bodner, E., \& Palgi, Y. (2015). When you're down and troubled: Views on the regulatory power of music. Psychology of Music, 43, 793-807. http://doi.org/10.1177/0305735614540360

Stapley, J. C. (2014). Music and emotion regulation among emerging adults in college. In F. R. Spielhagen \& P. D. Schwartz (Eds.), Adolescence in the 21st century: Constants and challenges (pp. 225-238). Charlotte, NC: Information Age Publishing, Inc.

Stoddart, W. H. B. (1904). A study of the emotions. Brain: A Journal of Neurology, 27, 509-521. http://dx.doi.org/10.1093/brain/27.4.509

Tamir, M. (2016). Why do people regulate their emotions? A taxonomy of motives in emotion regulation. Personality and Social Psychology Review, 20, 199-222. http://doi.org/10.1177/1088868315586325

Taruffi, L. \& Koelsch, S. (2014). The paradox of music-evoked sadness: An online survey. PLoS ONE, 9, e110490. http://doi.org/10.1371/journal.pone.0110490

Taylor, C. L. \& Friedman, R. S. (2015). Sad mood and music choice: Does the self-relevance of the mood-eliciting stimulus moderate song preference? Media Psychology, 18, 24-50. http://doi.org/10.1080/15213269.2013.826589 
Thayer, R. E., Newman, J. R., \& McClain, T. M. (1994). Self-regulation of mood: Strategies for changing a bad mood, raising energy, and reducing tension. Journal of Personality and Social Psychology, 67, 910-925. http://doi.org/10.1037/0022-3514.67.5.910

Thoma, M. V., Ryf, S., Mohiyeddini, C., Ehlert, U., \& Nater, U. M. (2012). Emotion regulation through listening to music in everyday situations. Cognition and Emotion, 26, 550-560. http://doi.org/10.1080/02699931.2011.595390

van Goethem, A. \& Sloboda, J. (2011). The functions of music for affect regulation. Musicae Scientiae, 15, 208-228. http://doi.org/10.1177/1029864911401174

Vuoskoski, J. K. \& Eerola, T. (2012). Can sad music really make you sad? Indirect measures of affective states induced by music and autobiographical memories. Psychology of Aesthetics, Creativity, and the Arts, 6, 204-213. http://doi.org/10.1037/a0026937

Watson, D. \& Clark, L. A. (1994). The PANAS-X: Manual for the positive and negative affect schedule-expanded form. The University of Iowa: Department of Psychological \& Brain Sciences Publications.

Webster, G. D. \& Weir, C. G. (2005). Emotional responses to music: Interactive effects of mode, texture, and tempo. Motivation and Emotion, 29, 19-39. http://doi.org/10.1007/s11031005-4414-0

White, E. L. \& Rickard, N. S. (2016). Emotion response and regulation to "happy" and "sad" music stimuli: Partial synchronization of subjective and physiological responses. Musicae Scientiae, 20, 11-25. http://doi.org/10.1177/1029864915608911

Zavoyskiy, S., Taylor, C. L., \& Friedman, R. S. (2016). Affect-incongruency in emotional responses to music. Psychomusicology: Music, Mind, and Brain, 26, 247-256. http://dx.doi.org/10.1037/pmu0000156 
Zbikowski, L. M. (2010). Music, emotion, analysis. Music Analysis, 29, 37-60.

http://doi.org/10.1111/j.1468-2249.2011.00330.x

Zhang, J., Yang, T., Bao, Y., Li, H., Pöppel, E., \& Silveira, S. (2018). Sadness and happiness are amplified in solitary listening to music. Cognitive Processing, 19, 133-139.

https://doi.org/10.1007/s10339-017-0832-7 


\section{APPENDIX A: DEMOGRAPHIC INFORMATION QUESTIONNAIRE}

Please answer the following questions about your background.

1. With which gender do you identify?
a. Woman
b. Man
c. Other (transgender, fluid, etc.)

2. What is your race/ethnicity/cultural background?
a. African American
b. Asian American or Asian descent
c. Biracial or multiracial
d. Caucasian or European American
e. Latina or Latino
f. Middle Eastern descent
g. Native American or American Indian
h. Pacific Islander
i. Other race/ethnicity/cultural background

3. What is your current year in school?
a. Freshman
b. Sophomore
c. Junior
d. Senior
e. Graduate Student

4. How old are you? 


\section{APPENDIX B: MODIFIED BRIEF MUSIC IN MOOD REGULATION SCALE (B-MMR)}

These items developed for this study. Each item's subscale is included after the item with an abbreviation key provided at the end; participants were unaware of this information.

Please read each of the following items carefully. Indicate the extent to which you agree or disagree with each item according to the scale below.

1. There's something comforting about Strongly Strongly immersing myself in a sad song Disagree Agree when I feel sad. (MC)

2. I like to listen to music that matches my mood, even if my mood is unpleasant. (MC)

3. When I'm sad, listening to happy

$$
1
$$

2

2

34
music feels jarring. (MC)

4. When I'm sad, I listen to sad music because it feels inappropriate to $\begin{array}{lllll}1 & 2 & 3 & 4 & 5\end{array}$ listen to happy music. (MC)

5. When everything feels sad, it helps me to listen to music that expresses my sad feelings. (Dis $-\mathrm{S}$ )

6. When I'm really sad, I feel like listening to some sad music. (Dis -

$\begin{array}{lllll}1 & 2 & 3 & 4 & 5\end{array}$
S)

7. When I'm sad about something, I listen to music that expresses my sadness. (Dis - S)

\section{Subscale Abbreviations:}

MC - Mood Congruency; Dis - S - Discharge - Sadness 


\section{APPENDIX C: REASONS FOR LISTENING TO SAD MUSIC QUESTIONNAIRE}

Please think about situations in which you choose to listen to sad music when you are already feeling sad. Rate how likely you are to choose sad music to listen to when experiencing sad emotions for each of the following reasons using the scale provided.

\begin{tabular}{|l|c|c|c|c|c|}
\hline & $\begin{array}{c}\text { Not at all } \\
\text { likely }\end{array}$ & $\begin{array}{c}\text { A little } \\
\text { likely }\end{array}$ & $\begin{array}{c}\text { Moderately } \\
\text { likely }\end{array}$ & $\begin{array}{c}\text { Quite a bit } \\
\text { likely }\end{array}$ & $\begin{array}{c}\text { Extremely } \\
\text { likely }\end{array}$ \\
\hline It helps me express my sadness. & 1 & 2 & 3 & 4 & 5 \\
\hline $\begin{array}{l}\text { It helps me remember people or } \\
\text { past experiences. }\end{array}$ & 1 & 2 & 3 & 4 & 5 \\
\hline It makes me feel sadder. & 1 & 2 & 3 & 4 & 5 \\
\hline $\begin{array}{l}\text { It helps me to better understand } \\
\text { the sadness I am feeling. }\end{array}$ & 1 & 2 & 3 & 4 & 5 \\
\hline $\begin{array}{l}\text { I always prefer listening to sad } \\
\text { music over other kinds of music, } \\
\text { even when I'm not sad. }\end{array}$ & 1 & 2 & 3 & 4 & 5 \\
\hline $\begin{array}{l}\text { It reminds me that other people } \\
\text { can feel the same way as me. }\end{array}$ & 1 & 2 & 3 & 4 & 5 \\
\hline I find it relaxing. & 1 & 2 & 3 & 4 & 5 \\
\hline $\begin{array}{l}\text { It is unpleasant listening to music } \\
\text { that isn't sad. }\end{array}$ & 1 & 2 & 3 & 4 & 5 \\
\hline It makes me feel energized. & 1 & 2 & 3 & 4 & 5 \\
\hline
\end{tabular}




\section{APPENDIX D: SONG SATISFACTION SCALE}

Please indicate the extent to which you Agree or Disagree with the following statements using the scale provided.

\begin{tabular}{|l|c|c|c|c|}
\hline & $\begin{array}{c}\text { Strongly } \\
\text { Disagree }\end{array}$ & Disagree & Agree & $\begin{array}{c}\text { Strongly } \\
\text { Agree }\end{array}$ \\
\hline I am satisfied with my song choice. & 1 & 2 & 3 & 4 \\
\hline $\begin{array}{l}\text { Listening to my song of choice was } \\
\text { unfulfilling. }\end{array}$ & 1 & 2 & 3 & 4 \\
\hline $\begin{array}{l}\text { If I could go back, I would choose a } \\
\text { different song to listen to. }\end{array}$ & 1 & 2 & 3 & 4 \\
\hline $\begin{array}{l}\text { It felt satisfying to listen to this } \\
\text { song. }\end{array}$ & 1 & 2 & 3 & 4 \\
\hline $\begin{array}{l}\text { Listening to my song of choice was } \\
\text { gratifying. }\end{array}$ & 1 & 2 & 3 & 4 \\
\hline
\end{tabular}




\section{APPENDIX E: SONG SELECTION SURVEY}

From the five choices provided, please select the option that matches the instructions you were given when selecting a song to listen to.

Select a single song to listen to that allows you to express the emotions you are feeling.

Select a single song to listen to that provides you with emotional support.

Select a single song to listen to that allows you to better understand the emotions you are feeling.

Select a single song to listen to that matches the emotions you are feeling.

Select a single song to listen to that will cheer you up.

Now please think about why you chose that specific song to listen to. Indicate the extent to which each of the following reasons played into your decision.

\begin{tabular}{|l|c|c|c|c|c|}
\hline & Not at all & A little & Moderately & Quite a bit & Extremely \\
\hline $\begin{array}{l}\text { I chose a song that would help me } \\
\text { express my emotions. }\end{array}$ & 1 & 2 & 3 & 4 & 5 \\
\hline $\begin{array}{l}\text { I chose a song that would give me } \\
\text { emotional support. }\end{array}$ & 1 & 2 & 3 & 4 & 5 \\
\hline $\begin{array}{l}\text { I chose a song that would help me } \\
\text { to better understand the emotions } \\
\text { I was feeling. }\end{array}$ & 1 & 2 & 3 & 4 & 5 \\
\hline $\begin{array}{l}\text { I chose a song because it would } \\
\text { match my emotions. }\end{array}$ & 1 & 2 & 3 & 4 & 5 \\
\hline $\begin{array}{l}\text { I chose a song that would help } \\
\text { cheer me up. }\end{array}$ & 1 & 2 & 3 & 4 & 5 \\
\hline
\end{tabular}




\section{APPENDIX F: SONG RATING SCALES}

\section{Song Rating Instructions}

1. Music listening and song ratings should only be completed in the lab using headphones without the presence of others or additional distractions.

2. Use Spotify to listen to each of the songs listed on your excel sheet.

a. Make sure song title, artist name, and album name all match the song you are listening to on Spotify

b. Listen to the song in its entirety.

3. After listening to each song, complete the song rating scales included below.

a. Each item corresponds with a single column in your excel spreadsheet

b. Indicate your rating of each item (the integer only) in the appropriate column in the row of the song to which it applies.

4. Do not discuss your ratings of any of the songs with any other raters. These ratings should be based on your own perceptions and should not be influenced by the perceptions or thoughts of others.

\section{Song Rating Scales}

Please indicate the extent to which the song you just listened to conveyed the following emotions using the scale provided.

\begin{tabular}{|c|c|c|c|c|c|c|}
\hline & & Not at all & A little & Moderately & Quite a bit & Extremely \\
\hline Q1 & Happiness & 1 & 2 & 3 & 4 & 5 \\
\hline Q2 & Sadness & 1 & 2 & 3 & 4 & 5 \\
\hline Q3 & Anger & 1 & 2 & 3 & 4 & 5 \\
\hline Q4 & Fear & 1 & 2 & 3 & 4 & 5 \\
\hline
\end{tabular}


Please indicate how arousing the song you just listened to was using the scale provided.

\begin{tabular}{|c|c|c|c|c|c|c|}
\hline & & Not at all & A little & Moderately & Quite a bit & Extremely \\
\hline Q5 & Calming & 1 & 2 & 3 & 4 & 5 \\
\hline Q6 & Arousing & 1 & 2 & 3 & 4 & 5 \\
\hline
\end{tabular}

Please indicate the speed of the song you just listened to using the scale provided.

\begin{tabular}{|c|c|c|c|c|c|c|}
\cline { 2 - 6 } \multicolumn{2}{c|}{} & Very Slow & Slow & Moderate & Fast & Very Fast \\
\hline Q7 & Speed & 1 & 2 & 3 & 4 & 5 \\
\hline
\end{tabular}

Please indicate the how familiar you are with the song using the scale provided.

\begin{tabular}{|c|c|c|c|c|c|c|}
\cline { 2 - 6 } \multicolumn{2}{l|}{} & Not at all & A little & Moderately & Quite a bit & Extremely \\
\hline Q8 & Familiarity & 1 & 2 & 3 & 4 & 5 \\
\hline
\end{tabular}

